\title{
Animal models for evaluation of oral delivery of biopharmaceuticals
}

\author{
Harloff-Helleberg, Stine; Nielsen, Line Hagner; Nielsen, Hanne Mørck
}

Published in:

Journal of Controlled Release

Link to article, DOI:

10.1016/j.jconrel.2017.09.025

Publication date:

2017

Document Version

Peer reviewed version

Link back to DTU Orbit

Citation (APA):

Harloff-Helleberg, S., Nielsen, L. H., \& Nielsen, H. M. (2017). Animal models for evaluation of oral delivery of biopharmaceuticals. Journal of Controlled Release, 268, 57-71. https://doi.org/10.1016/j.jconrel.2017.09.025

\section{General rights}

Copyright and moral rights for the publications made accessible in the public portal are retained by the authors and/or other copyright owners and it is a condition of accessing publications that users recognise and abide by the legal requirements associated with these rights.

- Users may download and print one copy of any publication from the public portal for the purpose of private study or research.

- You may not further distribute the material or use it for any profit-making activity or commercial gain

- You may freely distribute the URL identifying the publication in the public portal

If you believe that this document breaches copyright please contact us providing details, and we will remove access to the work immediately and investigate your claim 
1 Animal Models for Evaluation of Oral Delivery of Biopharmaceuticals

2

3 Stine Harloff-Helleberg ${ }^{1}$, Line Hagner Nielsen ${ }^{2}$, Hanne Mørck Nielsen ${ }^{1, A}$

$4{ }^{1}$ Department of Pharmacy, Faculty of Health and Medical Sciences, University of Copenhagen, 5 Universitetsparken 2, 2100 Copenhagen $\varnothing$, Denmark

$6{ }^{2}$ Department of Micro- and Nanotechnology, Technical University of Denmark, Ørsteds Plads 345C, 2800

7 Kgs. Lyngby, Denmark

8

9 AC Corresponding author: Department of Pharmacy, University of Copenhagen, Universitetsparken 2, 2100

10 Copenhagen, Denmark, Tel: +45 353363 46. Email address: hanne.morck@sund.ku.dk (H. Mørck Nielsen) 


\section{Abstract}

12 Biopharmaceuticals are increasingly important for patients and the pharmaceutical industry due to their ability to treat and, in some cases, even cure chronic and potentially life-threatening diseases. Most biopharmaceuticals are administered by injection, but intensive focus on development of systems for oral delivery of biopharmaceuticals may result in new treatment modalities to increase patient compliance and reduce product cost.

In the preclinical development phase, use of experimental animal models is essential for evaluation of new formulation designs. In general, limited oral bioavailability of biopharmaceuticals, of just a few percent, is expected, and therefore, the animal models and the experimental settings must be chosen with outmost care. More knowledge and focus on this topic is highly needed, despite experience from the numerous studies evaluating animal models for oral drug delivery of small molecule drugs. This review highlights and discusses pros and cons of the most currently used animal models and settings, and in addition also the influence of anesthetics and sampling methods for evaluation of drug delivery systems for oral delivery of biopharmaceuticals primarily with examples on insulin.

\section{Keywords}

Peptides, proteins, insulin, in situ perfusion, in vivo, macromolecules

Abbreviations: API, active pharmaceutical ingredient; BE, bioequivalence; $C L S M$, confocal laser scanning microscopy; DDS, drug delivery system; ELISA, enzyme-linked immunosorbent assay; EMA, European Medicines Agency; FDA, U.S. Food \& Drug Administration; FITC, fluorescein isothiocyanate; GI, gastrointestinal; GLP1, glucagon-like peptide 1; HPLC, high-performance liquid chromatography; IV, intravenous; IVIVC, in vitro in vivo correlations; IVIVR, in vivo in vitro relationship; LC-MS, liquid chromatography-mass spectrometry; $\mathrm{P}_{\text {app }}$, apparent permeability; $\mathrm{P}_{\text {eff, }}$ effective permeability; $\mathrm{PET}$, positron-emissions-tomography; QSAR, quantitative structural activity relationship; SC, subcutaneous; SEM, standard error of the mean; SPECT/CT, single-photon emission computed tomography; TEM, transmission electron microscopy 


\section{Introduction}

56 During the last decades, biopharmaceuticals (e.g. peptides and proteins) have become a growing part of the pharmaceutical industry, and the drugs of choice for treatment of numerous chronic and potentially life-threatening diseases e.g. cancer, inflammatory diseases and diabetes [1,2]. At the time being, subcutaneous or intravenous administration of biopharmaceuticals is still the most widely used route of administration. Currently, approximately 100 biopharmaceutical drug compounds are on the market worldwide, and seven of these are in top 10 of the most selling drugs [3-6]. It is estimated that approximately 270 peptides are currently tested in clinical trials and more than 500 are in preclinical development [5]; numbers providing good indications towards a rapidly growing market. Oral delivery of drugs is the preferred route of dosing due to ease of administration, high patient convenience and thus, compliance and relatively low costs [6,7]. Desmopressin, a synthetic analogue of vasopressin, serves as a positive example of a marketed oral peptide drug formulation, along with promising results for oral delivery of semaglutide, a GLP-1 analogue. But despite these successes, there are many obstacles to deliver biopharmaceuticals in general via the oral route. Among those obstacles are the large molecular size of the drug together with their low stability in biological fluids, mainly caused by enzymatic degradation and low $\mathrm{pH}$ in the gastrointestinal (GI) environment. Moreover, biopharmaceuticals are known to have a low permeation across the intestinal mucosa $[1,3,5,8-10]$, resulting in a very low bioavailability after oral dosing [11]. Due to the limited bioavailability, selection of the correct animal model and experimental settings are key elements when evaluating oral delivery of biopharmaceuticals and the appurtenant drug delivery systems (DDS). Furthermore, all experimental variables need to be assessed, including how they can potentially affect the readout of the experiment. A recent review by Sjögren et al. [12] addresses the importance of anatomy and physiology variability between various species when conducting animal studies. The aim of the present review is to give some guidelines when conducting animal studies, both in vivo, in situ and ex vivo, to assess the potential of oral DDS containing biopharmaceuticals. The models will be described and discussed including their respective advantages and disadvantages. In the following, ex vivo is defined as studies, where the organs are placed in an external environment, whereas in in situ studies, the organ is studied as a whole in the living animal. Furthermore, in vivo studies are described, when investigating the biopharmaceutical in the whole living animal. In addition, in vitro models, refers to experiments with cells or excised tissue outside their normal biological environment, and these will only briefly be described. For a more detailed review on in vitro models, the reader is referred to recent reviews $[12,13]$. In silico modelling will also only be briefly touched upon, as this is excellently addressed in a recent review [14].

\section{Drug delivery system designs for oral delivery of biopharmaceuticals}

89 After almost 100 years of research within the area of oral delivery of biopharmaceuticals [10], more knowledge is still needed to succeed within this topic. As of today, the most promising attempts to succeed with oral delivery of biopharmaceuticals include a combination of enteric coating for delivery to the site of absorption. Moreover, addition of protease inhibitors and permeation enhancers to the DDS may enhance the absorption of the biopharmaceuticals through the intestinal membrane [10]. Novel approaches of utilizing e.g. microneedles in the GI tract may further facilitate the membrane transport [15]. These approaches optimally ensure delivery of an intact drug molecule at or into the surface of the intestinal membrane (the site of absorption), and the transport through the membrane. Delivery of intact and solubilized drug to the site of absorption is challenging due to varying $\mathrm{pH}$ in the $\mathrm{Gl}$ tract, ranging from $\mathrm{pH}$ 1- 
2 in fasted stomach to $\mathrm{pH}$ of 5.5-6.5 in the duodenum, and pH 5.5-7.0 in the large intestine [6]. In both the stomach and intestine, numerous digestive enzymes are present together with an intestinal flora, the microbiota, providing a very unstable environment for the biopharmaceuticals [16]. By utilizing an entericcoated DDS for protection, it is possible to avoid degradation of the drug and have the biopharmaceutical to pass the stomach and reach the small intestine for absorption. Moreover, it is important to carefully consider the impact of the physicochemical properties, e.g. molecular weight, biophysical stability in the harsh GI environment, lipophilicity and ionization constant of the specific drug for the delivery potential. This needs to be assessed in relation to the biological barriers considering proteolysis in the stomach, variable $\mathrm{pH}$ values and poor permeation through the biological membranes, restricting the absorption from the GI tract. It is of course essential to ensure that the biological activity of the biopharmaceutical is maintained when developing an oral DDS $[6,17]$. The majority of ongoing research includes calcitonin and insulin as model drugs due to their frequent dosing and clinical importance thus, high economic impact [5]. In literature, a variety of in vivo, in situ and ex vivo models have been used involving various animal species, but also many different experimental settings have been utilized [12]. Table 1 and 2 provide an overview of the animal studies in literature with oral DDS for insulin (Table 1) and other biopharmaceuticals (Table 2).

\section{Barriers to overcome for successful oral delivery}

Apart from preventing degradation, a main obstacle for successful oral delivery of biopharmaceuticals is the limited permeation across the intestinal membrane (Figure 1). Thus, researchers aim to increase the permeation across the biological membrane by various means $[3,8,10]$. Often, the complexity and variability of the gut physiology and the influence that this may have on absorption is underestimated, when designing DDS to be absorbed from the small intestine. It is essential to include animal studies in the early development phase in order to integrate the dynamic processes happening simultaneously in the body, whereby the iterative design process towards an optimized DDS will have a greater chance of success [18]. Two major determinants for successful absorption from the GI tract are dissolution and permeation, and as biopharmaceuticals are generally freely soluble in aqueous medium with a logP value $<0$ dissolution will usually not be the rate-limiting step $[19,20]$. It can therefore be useful to assess the membrane permeability to the given biopharmaceutical in vitro before moving to animal models. Examples of in vitro permeability experiments include use of excised tissue, cultured cells, artificial membranes and isolated mucosal cells $[18,19]$. Following positive in vitro permeability results, it is essential to perform animal studies. When selecting an animal model, it is important to keep in mind the impact of the anatomical and the physiological differences and similarities between and within species. Even though, the morphology of the intestinal membrane may be seen as comparable in broad terms across species, drug transporter proteins, intestinal metabolizing enzymes, microorganisms, fluid volume and flow, and concentrations of intestinal secretions can differ from species to species, which is crucial to keep in mind [18]. Furthermore, $\mathrm{pH}$ values in the stomach and intestine may also differ from the animal in comparison to humans, and the total absorptive area of the intestine is different [12]. In addition, the physiology of the intestine will change with age, and will thus, be different in children and in the elderly population compared to middleaged adults. This review does not go into depth with the differences in Gl physiology, and how it will influence the permeability of intestinal mucosa to oral biopharmaceuticals. 

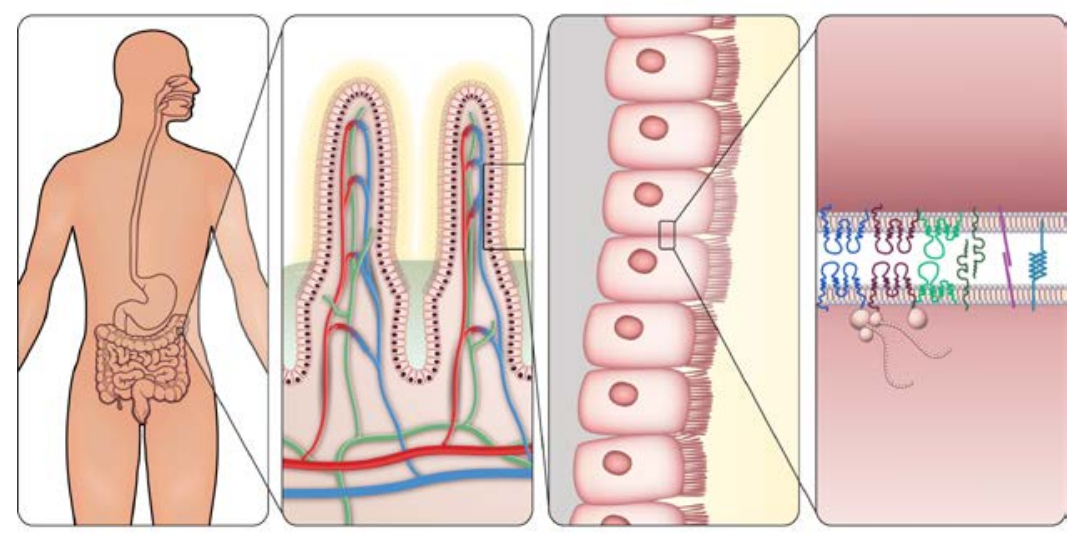

140 Figure 1: Graphic showing the in vivo barriers in the intestine following oral administration. 
Table 1: Overview of studies evaluating oral delivery of insulin in animals

\begin{tabular}{|c|c|c|c|c|}
\hline Administration route & Specie & Blood sampling & Quantification method & References \\
\hline Colonic injection & Rats, diabetic & Portal vein & Blood glucose & {$[21]$} \\
\hline Duodenal administration & Rats & Jugular vein & Blood glucose, ELISA and radioimmunoassay & {$[7,22-25]$} \\
\hline Duodenal cannulation & Rats, diabetic & Carotid artery & Blood glucose & {$[26]$} \\
\hline Duodenal cannulation & Rabbits & Carotid artery & Blood glucose & {$[27]$} \\
\hline Ex vivo ileum & Rabbits & N.S. & 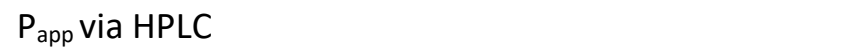 & {$[28,29]$} \\
\hline Ex vivo ileum & Sheep & N.S. & Papp via HPLC & [29] \\
\hline Ex vivo jejunum & Sheep & N.S. & Histology test & {$[29]$} \\
\hline Ex vivo jejunum, duodenum and ileum & Rats & N.S. & HPLC and CLSM & [30-32] \\
\hline Ex vivo jejunum and colon & Rats & N.S. & Lactate dehydrogenase assay & [33] \\
\hline Ex vivo permeation of colon & Rats, diabetic & N.S. & HPLC & {$[21]$} \\
\hline In situ duodenal and ileal loop & Rabbits, diabetic & Jugular vein & Blood glucose & [34] \\
\hline In situ ileal loop perfusion & Rats & Caudal vein & Blood glucose & [35] \\
\hline In situ isolated intestinal loop & Rats, diabetic & N.S. & $\begin{array}{l}\text { Histology of follicular mucosa (Peyer's patches) up to } \\
4 \text { h using fluorescence microscopy }\end{array}$ & {$[36]$} \\
\hline In situ jejunum, ileum and colon & Rabbits & $\begin{array}{l}\text { Mesenteric } \\
\text { vein }\end{array}$ & Radioimmunoassay & [34] \\
\hline \multirow[t]{3}{*}{ In situ single pass perfusion } & Rats & N.S. & HPLC & {$[37]$} \\
\hline & Rats & Jugular vein & Blood glucose, ELISA, PET imaging & {$[28,38-41]$} \\
\hline & & & PET imaging and ELISA & \\
\hline Intestinal loop (injection) & Rats & N.S. & Fluorescence microscopy & {$[31,42,43]$} \\
\hline Intraduodenal injection & Rats, diabetic & Tail vein & $\begin{array}{l}\text { Blood glucose, enzyme immunoassay kit and blood } \\
\text { glucose }\end{array}$ & {$[44-46]$} \\
\hline Intraduodenal injection & Rats, diabetic & N.S. & Blood glucose & [47] \\
\hline Intragastric injection & Rats & Tail vein & Blood glucose & {$[48-50]$} \\
\hline Intragastric gavage & Rats, diabetic & Eye & Glucose oxidase and plasma glucose & {$[51]$} \\
\hline
\end{tabular}


Table 1. Continued.

\begin{tabular}{|c|c|c|c|c|}
\hline Administration route & Specie & Blood sampling & Quantification method & References \\
\hline Intragastric gavage & Rats, diabetic & Tail vein & Blood glucose and ELISA & {$[52-54]$} \\
\hline Intragastric gavage & Rats, diabetic & Tail vein & Blood glucose and HPLC & [55] \\
\hline Intragastric gavage & Rats, diabetic & Leg vein & Blood glucose and ELISA & [56] \\
\hline Intragastric injection & Rats, diabetic & Tail vein & Blood glucose & {$[50]$} \\
\hline Intragastric injection & Mice, diabetic & Tail vein & Blood glucose and ELISA & [58] \\
\hline Intragastric placement & Pigs & Femoral vein & Blood glucose, ELISA and radiographs & [15] \\
\hline Intrajejunal administration & Rats & Tail or jugular vein & Blood glucose, ELISA and histology & {$[60]$} \\
\hline Intrajejunal injection & Mice & Tail vein & ELISA & [61] \\
\hline Intrajejunum injection & Pigs & Descending aorta & Blood glucose and ELISA & [62] \\
\hline $\begin{array}{l}\text { Oral administration (tablet, deep in the } \\
\text { throat) }\end{array}$ & Mice, diabetic & Eye & Blood glucose & {$[63,64]$} \\
\hline $\begin{array}{l}\text { Oral administration (tablet, deep in the } \\
\text { throat) }\end{array}$ & Rats & Tail vein & Blood glucose and ELISA & [65-69] \\
\hline Oral gavage (capsules) & Rats, diabetic & N.S. & Blood glucose & [78] \\
\hline Oral gavage (capsules) & Rats & Tail vein & Blood glucose and ELISA & $\begin{array}{l}{[30,59,79,8} \\
0]\end{array}$ \\
\hline Oral gavage (capsules) & Rats, diabetic & Eye & Blood glucose, histology and mucoadhesion & {$[81]$} \\
\hline Oral gavage (capsules) & Rabbits & N.S. & ELISA & [82] \\
\hline Oral gavage of hydrogel & Rats, diabetic & N.S. & Blood glucose & [83] \\
\hline Oral gavage of suspension & Mice, diabetic & Tail vein & Blood glucose & [84-86] \\
\hline Oral gavage of suspension & Mice, diabetic & Eye & Blood glucose and ELISA & {$[87,88]$} \\
\hline
\end{tabular}


Table 1. Continued.

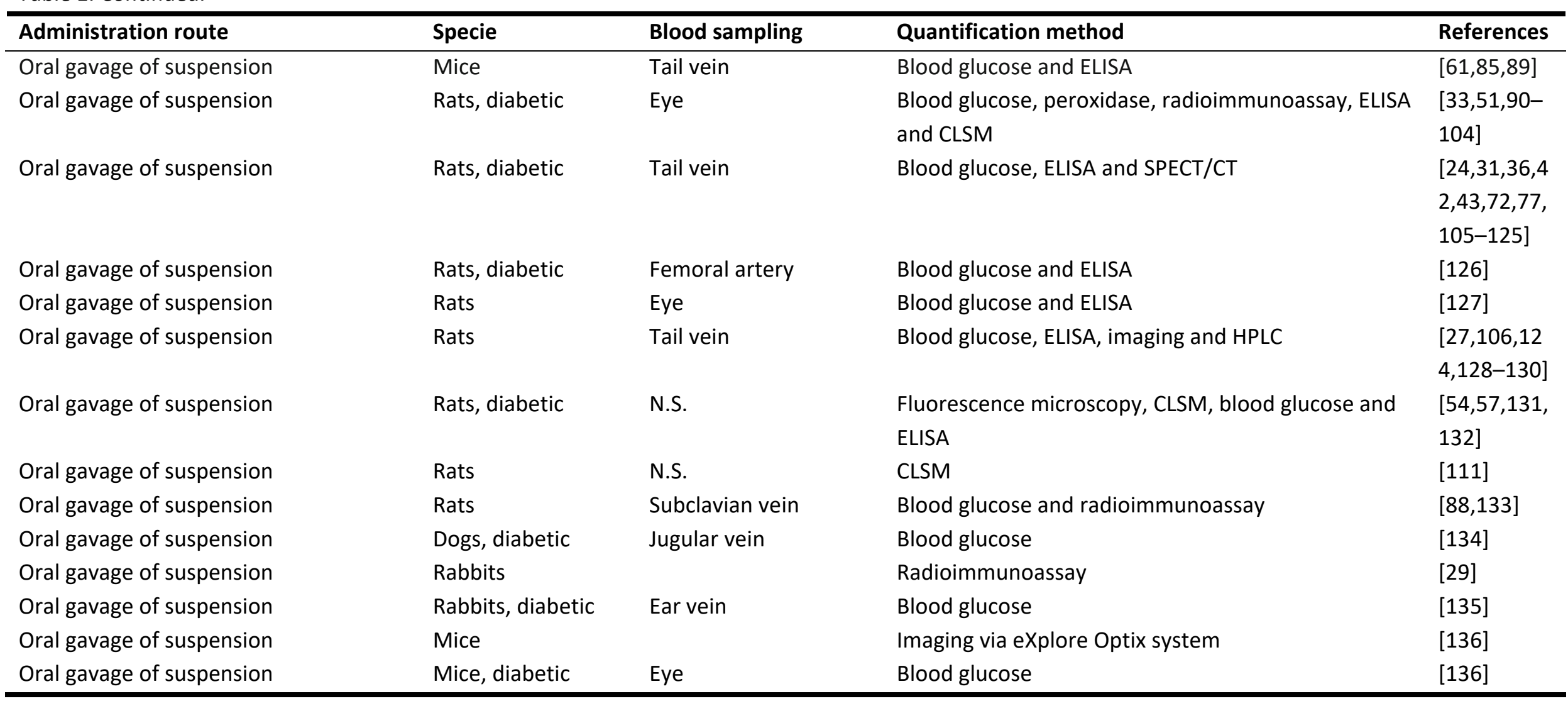


Table 2. Overview of studies evaluating oral delivery of biopharmaceuticals (except for insulin) in animals.

\begin{tabular}{|c|c|c|c|c|c|}
\hline Biopharmaceutical & Administration route & Specie & Blood sampling & Quantification method & References \\
\hline $\begin{array}{l}\text { Antihypertensive } \\
\text { peptide (Val-Leu-Pro- } \\
\text { Val-Pro-Arg) }\end{array}$ & Oral gavage of suspension & $\begin{array}{l}\text { Rats, } \\
\text { hypertensive }\end{array}$ & $\mathrm{N} / \mathrm{A}$ & Blood pressure by the tail cuff method & [137] \\
\hline Antide & $\begin{array}{l}\text { Oral administration (tablet, } \\
\text { deep in the throat) }\end{array}$ & Rats & Tail vein & LC-MS of plasma & [138] \\
\hline Buserelin & Intraduodenal injection & Rats & Carotid artery & Radioimmunoassay & [139] \\
\hline Exendin-4 & In situ perfusion & Rats & Heart puncture & Immunoassay kit & {$[35,140]$} \\
\hline Exendin-4 & In situ perfusion & Rats & N.S. & Fluorescence microscopy & {$[141]$} \\
\hline Exendin-4 & Intraintestinal injection & Mice, diabetic & Tail vein & Blood glucose & {$[141]$} \\
\hline GLP1 & Jejunal placement & Rats & Tail vein & Blood glucose & [49] \\
\hline GLP1 & Oral gavage of suspension & Mice & N.S. & Blood glucose & {$[142]$} \\
\hline GLP1 & Oral gavage of suspension & Mice, diabetic & Tail vein & $\begin{array}{l}\text { Radioimmunoassay, intraperitoneal } \\
\text { glucose tolerance test, blood glucose, } \\
\text { near-infrared imaging and X-ray }\end{array}$ & {$[143,144]$} \\
\hline GLP1 & Oral gavage of suspension & Rats & $\begin{array}{l}\text { Jugular vein, carotid } \\
\text { artery and eye }\end{array}$ & ELISA & {$[143,145]$} \\
\hline GLP1 & Oral gavage of suspension & Rats, diabetic & Tail vein & $\begin{array}{l}\text { Blood glucose, ELISA and pancreatic } \\
\text { insulin after euthanisation }\end{array}$ & {$[146,147]$} \\
\hline $\begin{array}{l}\text { Granulocyte } \\
\text { colony-stimulating } \\
\text { factor }\end{array}$ & Oral gavage of suspension & Rats & Tail vein & ELISA & [148] \\
\hline Heparin (conjugate) & Oral gavage of suspension & Mice & Heart puncture & Anti-factor assay kit & [149] \\
\hline Leuprolide & Ex vivo, intestine & Rabbits & N.S. & Radioimmunoassay & {$[150]$} \\
\hline Leuprolide & $\begin{array}{l}\text { Intrajejunum, intraileum or } \\
\text { intracolonic injection }\end{array}$ & Rats & $\begin{array}{l}\text { Portal vein and aortic } \\
\text { artery }\end{array}$ & Radioimmunoassay & [150] \\
\hline
\end{tabular}


Table 2. Continued

\begin{tabular}{|c|c|c|c|c|c|}
\hline Biopharmaceutical & Administration route & Specie & Blood sampling & Quantification method & References \\
\hline Leuprolide & $\begin{array}{l}\text { Oral administration (tablet, } \\
\text { deep in the throat) }\end{array}$ & Rats & Tail vein & LC-MS of plasma & [151] \\
\hline Leuprolide & Oral gavage of suspension & Rats & Tail vein & LC-MS of plasma & {$[11]$} \\
\hline $\begin{array}{l}\text { Protein Alpha } \\
\text { crystallin }\end{array}$ & Oral gavage of suspension & Mice & Eye & ELISA & [153] \\
\hline Salmon calcitonin & Ex vivo, intestine & Rats & Retroorbital & $\begin{array}{l}\text { Fluorescence spectroscopy, ELISA and } \\
\text { histology }\end{array}$ & [154] \\
\hline Salmon calcitonin & In situ single pass perfusion & Dogs & Portal vein & Radioimmunoassay & [155] \\
\hline Salmon calcitonin & Intraduodenal injection & Rats & Tail vein & ELISA & [156] \\
\hline Salmon calcitonin & Intraduodenal injection & Rats & Eye & $\begin{array}{l}\text { Colorimetric calcium by UV } \\
\text { spectrophotometer }\end{array}$ & [26] \\
\hline Salmon calcitonin & Intrajejunal injection & Rats & Tail vein & ELISA & [157] \\
\hline Salmon calcitonin & Intrajejunal injection & Rats & Heart puncture & Colorimetric method & [158] \\
\hline Salmon calcitonin & Oral gavage (capsules) & Rats & Tail vein milking & ELISA & [157] \\
\hline Salmon calcitonin & Oral gavage of suspension & Rats & Intestinal tissue & CLSM and fluorescence & {$[162,163]$} \\
\hline Salmon calcitonin & Oral gavage of suspension & Rats & Jugular vein & Calcium assay & {$[163,164]$} \\
\hline Salmon calcitonin & Oral gavage of suspension & Rats & Saphenous vein & Calcium assay & [165-167] \\
\hline Salmon calcitonin & Oral gavage of suspension & Rats & Tail vein & $\begin{array}{l}\text { Calcium assay, colorimetric method } \\
\text { and ELISA }\end{array}$ & [168-172] \\
\hline
\end{tabular}


Abbreviations used in the tables: CLSM: Confocal laser scanning microscopy, ELISA: enzyme-linked immunosorbent assay, HPLC: High-performance liquid chromatography, LC-MS: Liquid chromatography-mass spectrometry, N/A: Not applicable, N.S.: Not stated, UV: ultra-violet. 


\section{Ex vivo and in situ models}

Ex vivo models refer to experiments in live animals with the organs placed in external environments ensuring lowest possible change in native conditions. Similar to studies with ex vivo models, in situ models may also be used and has the advantage that the whole organ is studied intact in a living animal (Table 3). Ex vivo and in situ studies count for 14 and $11 \%$ of the total number of conducted animal studies, for studies with insulin (Figure 2A) and other biopharmaceuticals, respectively (Figure 2B) (information from Table 1 and 2). In Figure 2, the in situ studies and intestinal administration have been divided into two columns, these can be similar investigations, but the intestinal administration refers to either injection or placement of the DDS in the intestine, whereas the in situ studies describes investigations utilizing a flow of medium through the intestinal segment(s). In situ perfusion of intestinal segments in the Gl tract of rodent, typically rats or alternatively rabbits, are frequently used to study the permeation and absorption kinetics of drugs. Under those experimental settings, intestinal segments can be cannulated and the drug formulation in solution or suspension with or without DDS can be flushed through the isolated intestinal section. This procedure is referred to as the single-pass perfusion model, but as an alternative is the Doluisio approach, a closed-loop model, where the intestinal segment is filled with the solution or suspension throughout the entire experiment $[173,174]$. Both models have shown to provide intestinal membrane permeability values correlating closely to human data for small molecules [173]. The biggest advantage of the in situ methods compared to in vitro techniques is the presence of an intact blood and nerve supply in the live animals [18]. Rat and human jejunum effective permeability estimates of passively absorbed drugs in solution correlate highly for small molecules, and both can be used with precision to predict in vivo oral absorption of such drugs in man [175]. An advantage with in situ perfusion studies is that the whole intestine can be perfused or merely selected small segments, depending on which investigations are initiated. The predictability of the rat in situ perfusion model appears to be useful for the prediction of active uptake in humans, as rats have similar patterns of expression of the small intestinal membrane transporters as humans [176]. A recent study used in situ closed intestinal loops in rats to identify the region-dependent effect of potential absorption enhancers, penetratin and penetramax, indented for oral delivery of insulin [40]. The intestinal segments studied were duodenum, jejunum, ileum and colon, and test solutions were administered directly to the loop segments $30 \mathrm{~min}$ after surgery. The experiment concluded that ileum and colon appeared to be the most effective target sites for the tested permeation enhancers, as explained by the higher level of protease activity in the upper small intestine [40]. In the same study, it was shown that the maximal absorption detected depended on the enhancer used. Carrier peptides are used in some studies as intestinal absorption enhancers in combination with for example insulin, and for e.g. L-penetratin, the most pronounced effect was observed in the ileum, followed by jejunum, duodenum and colon. In contrast, Dpenetratin resulted in the highest blood concentrations of insulin after dosing in the colon, and less after dosing in the duodenum, jejunum and then ileum, respectively [40]. Thus, due to such DDS dependent regional differences, it seems that no general recommendation is clear regarding which region to administer the formulation to. In general, knowledge of GI regional differences related to intestinal drug absorption and effect on the specific evaluated DDS is crucial when setting up an animal experiment. A recent review focused on the intestinal absorption pathways of insulin nanoparticles in animal models [177]. That review concluded that intestinal absorption of insulin-loaded nanoparticles is closely related to accumulation of the particles in Peyer's patches, primarily located in the distal ileum [178], whereas the pathway of delivery for DDS targeting enterocytes and/or tight junctions remains unclear [177]. 
Ex vivo models are also utilized to investigate membrane permeation of the biopharmaceutical and/or interaction of the DDS with the intestinal membrane. A subcategory of ex vivo models is ex situ models, where organisms are moved from their natural environment. Often used models in relation to studies on oral delivery of biopharmaceuticals are ex situ barrier models assessing transport of compounds across excised intestinal tissue. The use of Ussing chambers to predict oral absorption has previously been reviewed, and the reader is referred to those excellent reviews for more details on the experimental setup $[18,179,180]$. In the reviews by Sjögren et al. [12] and Lennernäs [179], it is highlighted that more knowledge is needed from such ex vivo studies especially regarding the regional intestinal effective permeation to form the basis of improved in silico models [179]. Since the publication of those reviews, a study has evaluated the permeation of fluorescein isothiocyanate (FITC)-labelled insulin ex vivo using fresh rat ileum mucosal tissue and compared the findings to in vitro data from Caco-2/HT-29-MTX-E12 cell cocultures [181]. The study showed that the apparent membrane permeability $\left(P_{a p p}\right)$ of insulin dosed in trimethyl chitosan nanoparticles was 1.34-fold higher compared to unmodified nanoparticles and 1.87-fold increased as compared to the use of micelles [181]. When comparing with in vitro data, the same trend was observed both with and without the presence of mucus (e.g. 1.10 vs. 1.16-fold increase with mucus and 1.14 vs. 1.23 -fold increase without mucus). Last, the study evaluated the DDS in animal studies after oral administration to diabetic rats. The blood glucose depression as observed $3 \mathrm{~h}$ after administration was found to be decreased 1.28-fold when comparing trimethyl chitosan nanoparticles to unmodified nanoparticles, whereas the decrease was 1.62 -fold when comparing trimethyl chitosan nanoparticles to micelles [181]. Thus, all three models showed the same ranking of the formulations despite more pronounced difference between the formulations in the in vitro experiment than in the in vivo study. How those data and thus models are related to efficacy studies in man is yet to be addressed. L-valine-appended PLGA particles for oral delivery of insulin has been studied using an ex vivo everted intestine method and applied complimentary to oral gavage administration to diabetic rabbits [182,183]. The ex vivo data showed $48 \%$ insulin transport across the intestine for PLGA particles compared to $91 \%$ for L-valine-appended PLGA after $60 \mathrm{~min}$. When tested in an animal model, the L-valine-appended PLGA showed a slightly sustained hypoglycemic response compared to the non-conjugated particles [183]. Those findings highlight the complexity of relating ex vivo data to in vivo findings. A more complex barrier must be overcome when administering a formulation orally compared to studying permeation across tissue ex vivo, resulting in a less pronounced difference between the DDS tested. Despite the advantage of using animal tissue with functional cells acting as a barrier for drug uptake, such experiments are time consuming to set up, but can be useful for screening and comparing DDS containing the same biopharmaceutical and beneficial to perform prior to in vivo studies [18]. 
A

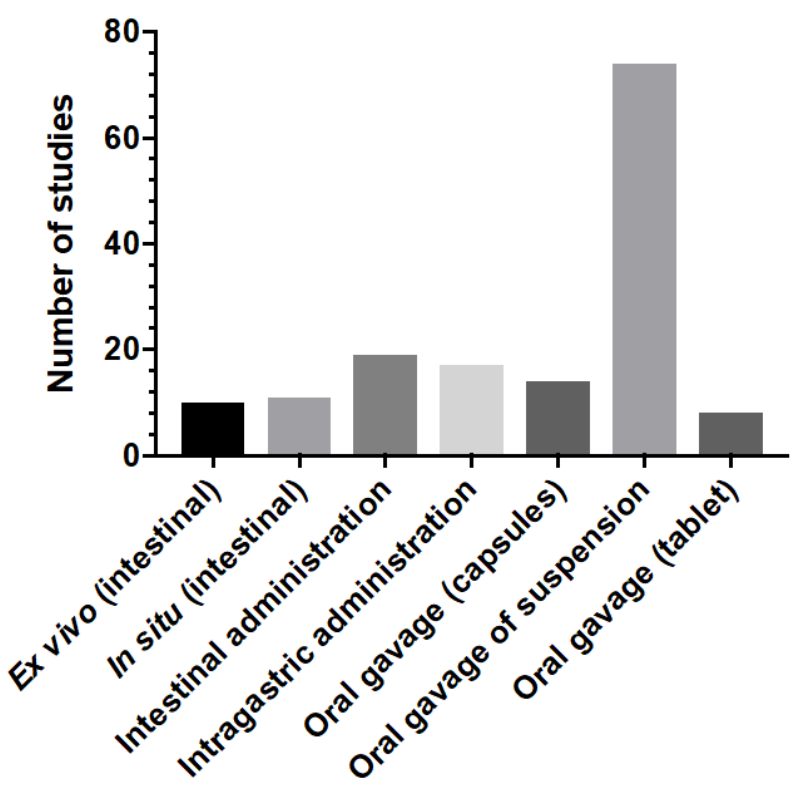

B

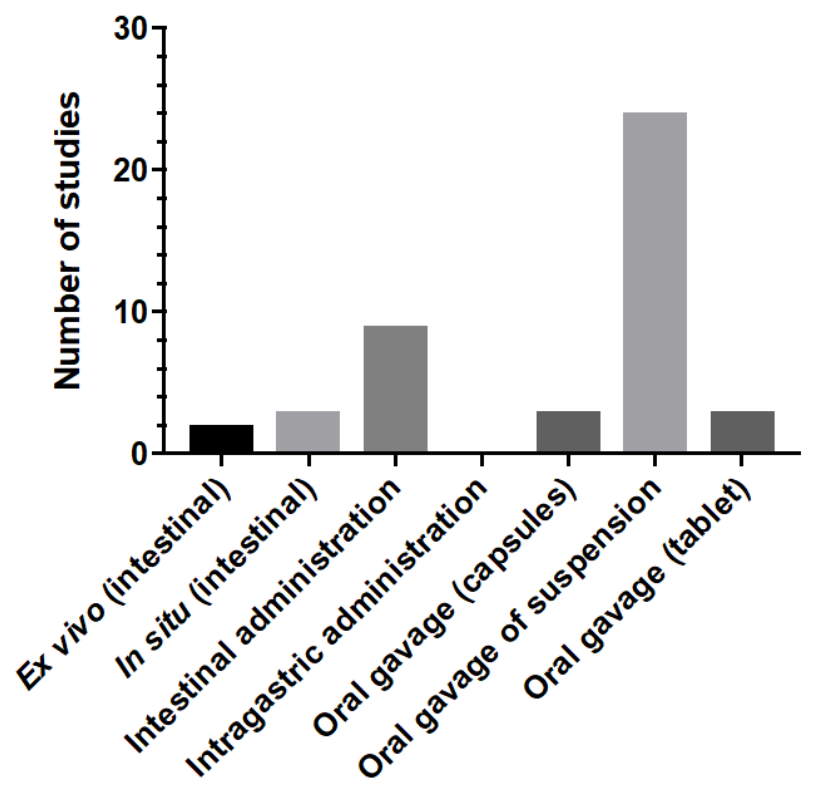

Figure 2: Overview of methods used to evaluate oral bioavailability of insulin (A) and other biopharmaceuticals (B) in vivo, ex vivo and in situ based on reviewed papers listed in Table 1 and 2.

Table 3: Overview of the pros and cons of the most used animal models for testing oral biopharmaceuticals

\begin{tabular}{|c|c|c|c|}
\hline Model & Aim & Pros & Cons \\
\hline Ex vivo & $\begin{array}{l}\text { Permeation and } \\
\text { absorption kinetics }\end{array}$ & $\begin{array}{l}\text { Regional differences can } \\
\text { be investigated }\end{array}$ & $\begin{array}{l}\text { Organisms are taken out of } \\
\text { the animal }\end{array}$ \\
\hline In situ & $\begin{array}{l}\text { Permeation and } \\
\text { absorption kinetics }\end{array}$ & $\begin{array}{l}\text { Regional differences can } \\
\text { be investigated. } \\
\text { Permeability data similar } \\
\text { to human data }\end{array}$ & $\begin{array}{l}\text { No data on passing through } \\
\text { the stomach }\end{array}$ \\
\hline In silico & $\begin{array}{l}\text { Mechanistic or } \\
\text { physiology-based } \\
\text { pharmaceokinetic } \\
\text { simulations }\end{array}$ & Does not include animals & $\begin{array}{l}\text { Does not include in vivo } \\
\text { solubility, stability and } \\
\text { metabolism }\end{array}$ \\
\hline $\begin{array}{l}\text { In vivo, healthy } \\
\text { animals }\end{array}$ & $\begin{array}{l}\text { Oral PK, PD and } \\
\text { bioavailability } \\
\text { evaluation }\end{array}$ & Better animal welfare & $\begin{array}{l}\text { Not conclusive to in } \\
\text { regards to disease } \\
\text { treatment }\end{array}$ \\
\hline $\begin{array}{l}\text { In vivo, diseased } \\
\text { animals }\end{array}$ & $\begin{array}{l}\text { Oral PK, PD, and } \\
\text { bioavailability } \\
\text { evaluation in diseased } \\
\text { animals }\end{array}$ & $\begin{array}{l}\text { Might be a more realistic } \\
\text { scenario to the human } \\
\text { situation }\end{array}$ & $\begin{array}{l}\text { Large variations in the } \\
\text { animal disease and } \\
\text { translation of data to man }\end{array}$ \\
\hline
\end{tabular}

\section{In silico models}

In silico approaches refer to computer simulations, ranging from applying simple rules to advanced dynamic modelling [18]. Modelling of compound solubility and membrane permeability plays an increasingly 
important role in drug discovery as they can be used as tools for early parameterization of mechanistic or physiology-based pharmacokinetic models or as starting points for refined models of a constrained series of chemical analogues $[19,184]$. Recently, in silico modelling has also been shown to be a useful tool to screen for new permeation enhancers and optimization of the physicochemical aspects of surfactant enhancer systems for oral delivery of proteins [185]. This study utilized a Random Forest Quantitative Structural Activity Relationship (QSAR) model, which was validated based on drug permeation data obtained from studies in Caco-2 cell culture models [185]. It was concluded that this approach serves as a robust strategy to systematically assess novel enhancers, but cannot, however, stand alone in the selection process. As for biopharmaceutical delivery, it is important to emphasize that the model as of today does not include aforementioned important parameters such as solubility, stability and metabolism [185]. A recent and very thorough review did, however, conclude that computational biopharmaceutical profiling is useful for early prediction of drug delivery strategies [14]. For more information on computational prediction, the reader is referred to this review [14].

Several commercial software for advanced in silico modelling are available, and three of the most commonly used, Simcyp 13.3, GastroPlus 8.0 and GI-Sim 4.1, were recently compared in relation to their capability to predict human intestinal drug absorption [186]. The study used a priori modelling with input data from 12 poorly water soluble drugs, all characterized by incomplete gastrointestinal absorption. It was concluded that the three types of software, all provide useful guidance in formulation development, with GI-Sim and GastroPlus favored over Simcyp due to better prediction of intestinal absorption of incompletely absorbed drugs [186]. Due to the black box nature of in silico software, it is generally recommended always to use several models to assess the same problem [12,187]. Moreover, it is very challenging to utilize for biopharmaceuticals due to the complicated degradation kinetics in lumen and during permeation. A highly important aspect to note is that accurate determinations of effective permeability $\left(P_{\text {eff }}\right)$ is needed to serve as a basis for future in silico predictions of oral delivery of biopharmaceuticals [12]. Moreover, it should be emphasized that the current in silico models does not include the complex nature of the in vivo environments determining the dissolution behavior [188].

\section{In vivo models}

In vivo models comprise the use of living species and in these cases a biopharmaceutical or DDS (containing a biopharmaceutical) are dosed and the effect is tested after appropriate sampling and/or testing. The use of reproducible and reliable in vivo models is highly important and required for development and marketing of drugs for oral administration. Biopharmaceuticals are, due to previously described physicochemical properties, characterized by a poor absorption across intestinal epithelium resulting in a very low oral bioavailability, but results from in vivo studies highly can depend on the species used [11]. As previously mentioned, it is therefore crucial to utilize a highly sensitive and reproducible model, in order to be able to detect the relatively low changes in pharmacokinetic and pharmacodynamics parameters relating to increased oral bioavailability. Additionally, knowledge about how experimental conditions such as specie morphology, dosing method, anesthesia, sampling method, use of animal disease models resembling human diseases and finally choice of analytical method for sample evaluation is of great importance and will be discussed in the following sections.

\subsection{Use of animal models with or without human disease symptoms and choice of specie}


One of the first choices to take when conducting animal studies is which specie to choose, and as seen from Figure 3, rats are used in $80 \%$ of the studies listed in Table 1 and 2. Mice represent another species often chosen, used in $11 \%$ of the insulin studies and in $16 \%$ of studies with other biopharmaceuticals. The physiological variations among species were recently reviewed [12], for which reason we will not go into detail with this topic, but rather focus on practical considerations when setting up an animal model. As rats are the most commonly used species in this context, it is important to know the basic differences compared to humans. The GI tract of a rat differs from that of man in several ways with the absence of gall bladder, higher nocturnal activity and different gut flora in the rat. In general, rats appear to provide good estimates for the prediction of absorption for compounds without dissolution problems such as biopharmaceuticals, and also highly reflect the human mucosal barrier in the intestine. Despite this, metabolic differences often lead to misleading predictions of oral bioavailability in humans $[18,19]$. Generally, when deciding on which animal model to apply, it is important to acknowledge that the bioavailability of biopharmaceuticals will be low even when avoiding the stomach and dosing directly to a specific part of the Gl tract, due to enzymatic degradation and poor membrane permeability of large molecules. Bioavailability is, however, found to be slightly higher when drugs are administered directly to the jejunum as compared to other segments of the intestine [5]. One aspect is the low apparent bioavailability; another is the correlation to humans. A comprehensive study compared the absorption of a whole range of small molecule drugs after dosing to the intestine [176]. The study showed that almost no overall correlation exists between oral bioavailability in rat and human $\left(r^{2}=0.29\right)$, whereas a correlation exists for intestinal permeability $\left(r^{2}=0.8\right)$, both when considering carrier-mediated transport as well as passive diffusion mechanisms [176]. When evaluating the expression level of transporters in duodenum, a moderate correlation $\left(r^{2}=0.56\right)$ exists between rat and human [176].

Another aspect to consider is whether to use animal models of human disease or healthy animals. Often the complexity and variability of gut physiology is underestimated, with only one or two variables being considered, this can either be in dosage form design or drug targeting approach [189]. Although strides have been made towards understanding the conditions and mechanisms responsible for absorption from a healthy gut, knowledge in this field is not yet complete. Even more significant is the lack of understanding the $\mathrm{Gl}$ environment in the diseased state. Functionalized dosage forms cannot be evaluated in a reproducible manner without a comprehensive understanding of the conditions to which they are subjected during in vivo testing. Understanding and taking into account the intestinal environment will not only open up for improved evaluation of new dosage form designs, but also improve experimental settings for in vitro and pre-clinical tests in animal models leading to better in vitro in vivo correlations (IVIVC), and thus, opening new avenues for oral DDS for biopharmaceuticals [189]. included use of animal models of human diseases, whereas this is only the case for $14 \%$ of non-insulin biopharmaceuticals (Table 2). The overall purpose of insulin administration is to replace the partly or complete lack of insulin in diabetic patients to prevent hyperglycemia [190]. Therefore, animal models of human diseases, in this case diabetic animals, are commonly used in order to gain insight of the efficacy of the administered DDS, eventually combined with knowledge of the mechanistic behavior of DDS [191]. 
A

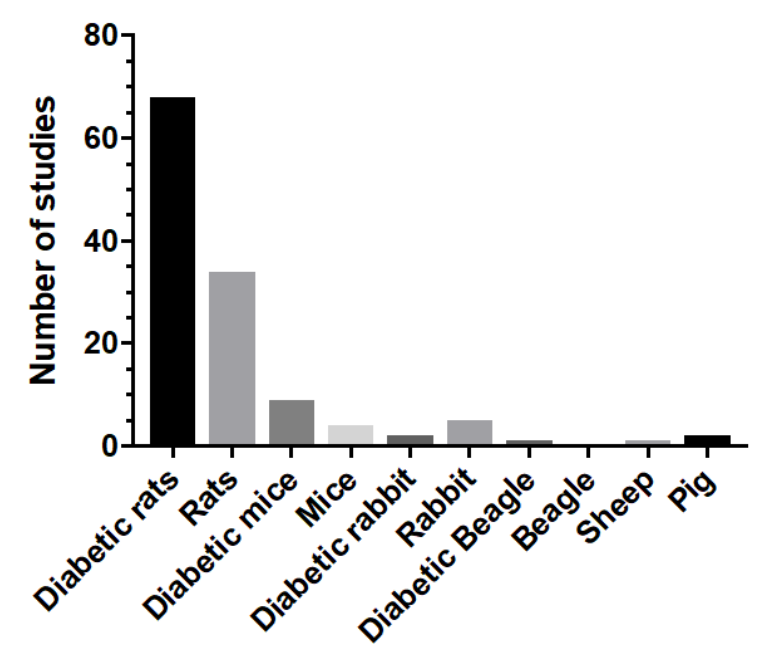

B

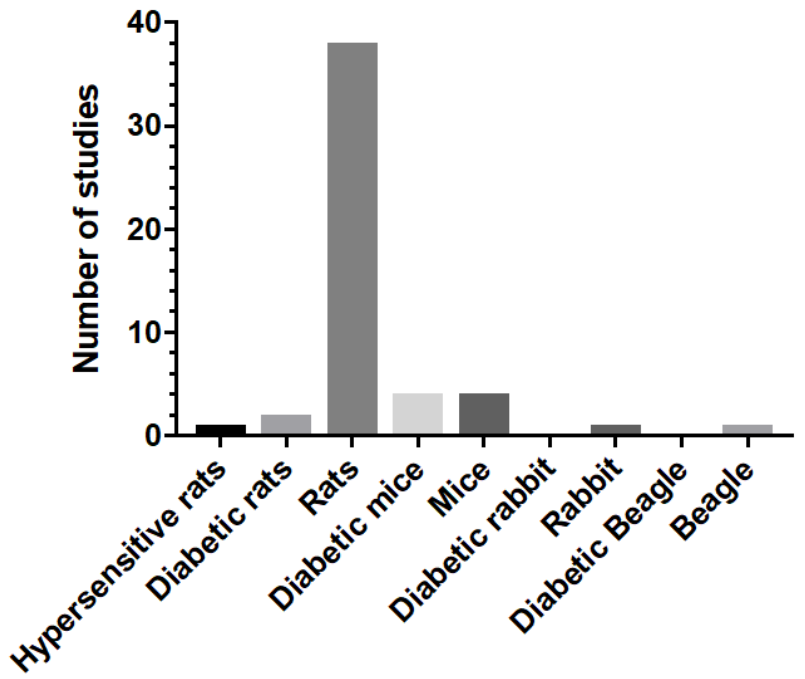

169

Figure 3: Overview of species used to evaluate oral bioavailability of insulin (A) and other biopharmaceuticals (B) in vivo, in situ or ex vivo. The data are based on reviewed papers, listed in Table 1 and 2 .

Numerous diabetic animal models exist, ranging from type 1 diabetic with spontaneously developing autoimmune diabetes, chemical ablation of pancreatic $\beta$-cells to type 2 diabetic models, where both obese and non-obese animals are included. Moreover, transgenic and knockout mouse models are also used within diabetic research $[190,192]$. In the reviewed papers (Table 1), the most commonly used diabetic model is streptozotocin-induced diabetes in rats or mice, done by single intraperitoneal injection of 40-60 $\mathrm{mg} / \mathrm{kg}$ streptozotocin to rats $[77,124]$ or $65-150 \mathrm{mg} / \mathrm{kg}$ to mice $[84,87]$ destroying the pancreatic $\beta$-cells [193]. The animals are considered diabetic once the plasma glucose level reaches $\geq 250 \mathrm{mg} / \mathrm{dL}$ for rats [77] and $\geq 300 \mathrm{mg} / \mathrm{dL}$ to $400 \mathrm{mg} / \mathrm{dL}$ for fasted $(12 \mathrm{~h})$ and fed mice [84,87]. Unfortunately, streptozotocin does not only harm the pancreatic $\beta$-cells [194], but also causes renal injury together with oxidative stress inflammation and endothelial dysfunction [195], which may influence the readout. Thus, as there are pros and cons associated with the various animal models and induction of human diseases in these, careful consideration should be taken to select animal model(s) representing the physiological diversity seen among human diabetic patients [191]. Animal disease models seldom copy all the aspects of the corresponding human disease, and are less characterized in the toxicology area compared to healthy animals. For securing this, several reviews suggests that more than one animal model of human disease should be included in the studies $[190,192,196]$. However, the exact same aspect of heterogeneity in diabetic expression and complications hereof considerably challenges data evaluation from animal studies, as it might be problematic to separate the drug-induced effect from disease-related complications [191]. Besides the always relevant discussion regarding the use of diseased animal models, it has been discussed that different species and strains behave differently both in relation to induction of diabetes and during treatment hereof [190]. In general, animal models cannot observe the differences seen between diabetic men and women when looking into for example cardiovascular complications [196]. Moreover, animals of different gender e.g. for diabetic rats, might also respond differently to experimentally induced stress and 
other metabolic variations, thus leading to gender-biased results. This is not seen in the same way for humans, but can influence the results of the animal studies substantially $[190,196]$.

No clear answer exists to the question of whether to use healthy or diseased animal models. Nonetheless, many caveats are associated with the use of animal models of human disease for assessment of oral DDS, when evaluating biopharmaceuticals with a known mode of action. Also, the animal welfare in terms of the complications associated with models of human diseases such as lack of histology control, diversity in disease expression leading to inclusion of more than one model of human disease, decreased life span and disease-related complications must be carefully considered [191,192]. In terms of species, healthy animals such as Sprague-Dawley rats, CD-1 mice, Beagle dogs, cynomolgus monkeys and mini pigs are the most commonly used models for evaluation of small molecule drugs due to good homogeneity [191]. For biopharmaceuticals, however, a more pronounced species specificity exists [191], as certain biopharmaceuticals are only active when administered to humans or chimpanzees and in other cases immunogenicity hampers full assessment in some species [197]. Such cases and alternative strategies to address such challenges have been thoroughly reviewed previously, for this reason the reader is referred here for further information [197].

\subsection{Effect of anesthesia on the readout}

Despite common knowledge in the scientific community of the fact that anesthesia is likely to affect the desired readout in animal models, not much literature exists addressing this aspect. When evaluating blood pressure, it is known that determination hereof is easier and with more accurate results when anaesthetizing the animals [198]. Contrary, anesthesia also introduces a significant variable, as it alters the blood pressure and cardiovascular reflexes among other physiological parameters [198].

It has been discussed from an animal welfare perspective and also from a scientific validity perspective within the area of musculoskeletal research that standard protocols for anesthesia and pain management should be developed and applied for animal models [199]. A study from 1983 shows that intraperitoneal injection of pentobarbital to healthy rats increases the blood glucose level by $33 \%$ already 3 min after administration, and returns to normal level only after 40 min [200]. Figure 4 depicts the effect on blood glucose level following subcutaneous (SC) administration of insulin to healthy male Sprague Dawley rats anaesthetized using the most commonly used anesthetics for such studies. The experiments were conducted after $12 \mathrm{~h}$. 


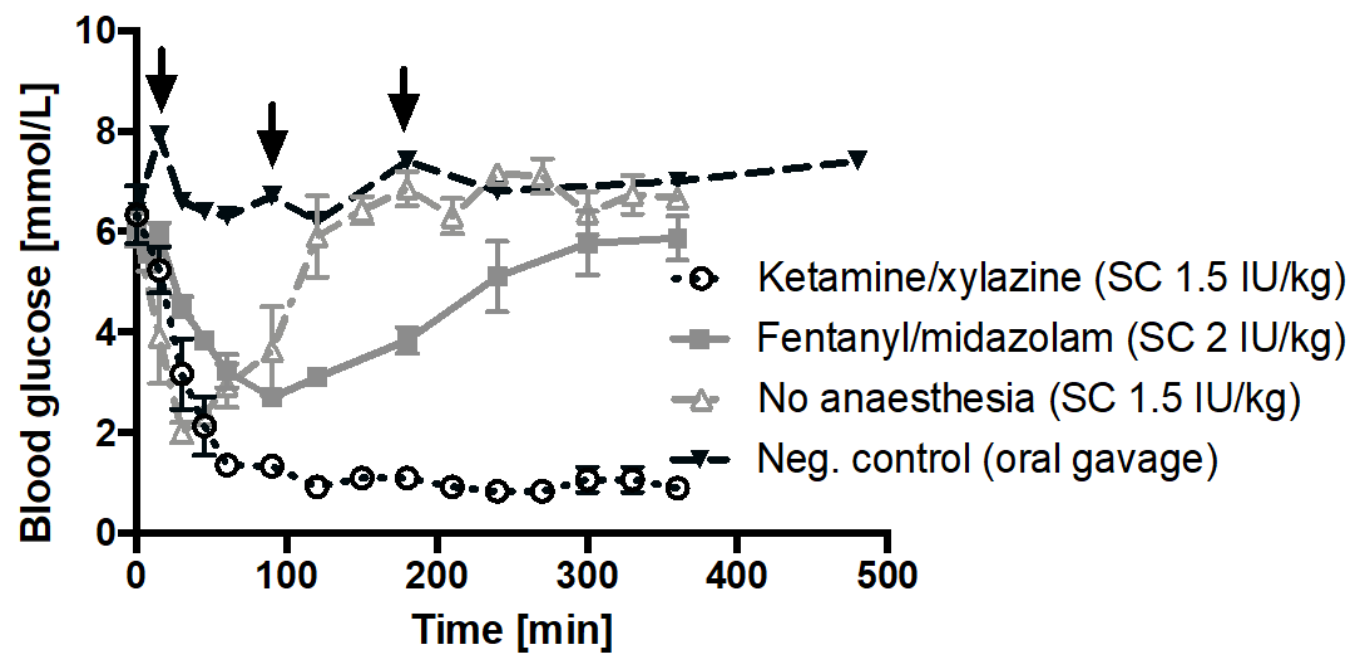

Figure 4: Effect of anesthesia on blood glucose level in healthy rats after subcutaneous (SC) dosing of insulin. The black arrows indicate momentary inhalation of isoflurane. The curves represent the average of three rats \pm SEM, except for the negative control where $n=1$. Blood samples were collected via the sublingual tongue vein.

The data depicted in Figure 4 clearly shows that a combination of ketamine/xylazine significantly decreases the blood glucose level, which is highly problematic if evaluating the unbiased effect of orally administered insulin. Fentanyl/midazolam does not have the same pronounced effect, but still results in a different profile as compared to non-anesthetized animals. More precisely, the maximum effect on the blood glucose level following insulin administration is delayed $60 \mathrm{~min}$ in the anaesthetized rats when compared to non-anaesthetized rats, and the recovery period is likewise significantly prolonged. It could be speculated, however, that the reduced recovery period in the non-anesthetized animals when compared to the anaesthetized animals is not only related to the effect of anesthesia, but also the blood sampling procedure. Thus, blood collection via the sublingual tongue causes a stress-induced elevated blood glucose level. Having said that, the authors experienced no sign of stress during handling in terms of diarrhea, urine excretion, screaming, fear of handling upon repeated blood sampling etc., which was the case when repeating the experiment using a restrainer. Conclusively, the effect of anesthesia is the most plausible explanation for variation in blood glucose level.

In the negative control group, the rats were subjected to momentary inhalation of isoflurane (shown by black arrows in Figure 4), and this is shown to increase the blood glucose level, similar to the previously described effect of pentobarbital [200].

Summing up, unless the selected animal model requires rigid restraint or if it is unethical from an animal welfare perspective due to the burden applied to the animal in conscious state after e.g. surgery, it is favored to use conscious models to avoid the impact from anesthesia [198]. Having said that, the stress applied to animals during surgeries such as cannulation of the intestine affects the animal for up to four days after surgery, and therefore, a recovery period of one week is highly recommended before conducting the experiment.

\subsection{Routes of administration and practical considerations}


Choosing the optimal administration route to the animal models requires careful considerations in order to minimize the risk of potential adverse events [201]. Some of the aspects to be considered include the expertise or training required for successful administration, the volume or size of the dosage form needed for administration of a sufficient dose, the precise administration site, $\mathrm{pH}$ of the test sample and to which extent animal restraint is needed [201]. When evaluating the effect of orally administered DDS for delivery of biopharmaceuticals, the most frequently used dosing method is by far oral gavage (Table 1 and 2, Figure 3).

Oral gavage, mimicking the intended route of administration to humans, requires restraint of the animals and correspondingly moderate training of the research personnel [201]. It has been shown that such restrain induces increase in both blood pressure and heart rate for up to $1 \mathrm{~h}$ following the dosing with gavage together with an increased stress level for the animals [202]. This can, however, be significantly reduced if practicing the procedure with the animals in advance. For mice, the stress level is already normalized on the second day of training [202], whereas rats requires three training days to maintain normal heart rate and blood pressure during oral gavage [203]. Besides proper training, the stress level associated with oral gavage can be decreased by dipping the gavage device in sucrose before dosing [202]. This is, however, not recommended when evaluating compounds such as insulin and GLP-1, where blood glucose level can be the desired readout. Also, soft gavage tubes are favored over stainless steel, as it induces less stress to the animals. Although, a drawback of using soft tubes is the risk of the animals biting the tubes causing even more stress to the animals and potentially exclude the animal from the experiment [201]. Another important aspect to consider is the dosing volume, which is not recommended to exceed 5 $\mathrm{mL} / \mathrm{kg}$. Larger volumes are likely to induce passive reflux, aspiration pneumonia, irritation in or even rupture of the GI tract [201,204] together with gastric distension, as rodents are not able to vomit [201]. Last, the solution or suspension administered should have room temperature not to induce unnecessary stress to the animals.

Oral administration of tablets or capsules is an alternative to oral gavage of liquids. As seen from Table 1 and 2, tablets are administered by placement in the deep throat thus, activating the swallowing reflex of the animal. The capsules are dosed by utilizing a commercially available steel device for the dosing of the capsules to the stomach. For both tablets and capsules, the size hereof must be scaled to the animal to which it is administered [201]. Although, certain sizes are recommended, it has been shown that entericcoated capsules of a commercially available size scaled to rats $(7.18 \mathrm{~mm}$ in length) do not reach the intestine after dosing to rats, but remains in the stomach, where they dissolve [205]. Interestingly, if shortening the capsules to a length of $3.5 \mathrm{~mm}$, they may be emptied from the stomach to the intestine. The study also concluded on a faster gastric emptying and transit of the capsule to the intestine in fed state animals as compared to animals in the fasted state [205]. The potential drawback of using the shortened capsules is a very limited loading capacity and also difficulty in handling the small capsules. Moreover, one should aim for achieving a homogeneous coating of the capsules (or tablets), and avoid scratches in the coating during handling and dosing, as this is likely to significantly impact the in vivo faith of the dosage form thus, induce sample variation. Also, powders can be administered via oral gavage, using a positive displacement pipetting device [206].

Compared to oral gavage, intragastric and intraintestinal administrations are more invasive procedures requiring surgical skills of the research personnel and also utilization of anesthesia. Nevertheless, when considering the previously mentioned correlation (section 6.1 ) between bioavailability in rat and human being $r^{2}=0.29$ and $r^{2}=0.8$ (after intragastric administration) [176], these methods are highly relevant to 
consider. Many variations of this procedure exist, including whether the DDS is administered by injection to the absorption site or dosed via an inserted cannula. In addition, the DDS may also be administered to different regions of the intestine and then it is important to consider if the DDS is administered under anesthesia (which is always the case for injections to the Gl tract) or after a recovery period in conscious cannulated animals. Regarding the effect of anesthesia, the reader is referred to the discussion in section 6.2 .

For injections or in situ studies, the material of the potential cannulas should be carefully considered [207]. A recent review provides, a very useful overview of pros and cons of the available materials [207]. In brief, the most important aspects to consider are the biocompatibility, the cannula inner wall diameter (in relation to the DDS administered) and risk of bacterial adherence. Moreover, flexibility of the material and chemical and temperature resistance are also important as a soft material of the cannula is less of a burden for the animal compared to a less flexible material [207]. The parameters are more or less essential depending on the length of the study and if the animals are to recover from surgery for a longer time before the experiment can start, or are anesthetized during the whole study. When working with conscious models, it is important to perform the surgical procedure under as clean conditions as possible, and therefore, autoclaving the cannula can be important [207].

Summing up, there are pros and cons for both oral gavage, intragastric or intraintestinal administration. Oral gavage is less invasive and requires moderate training of research personnel, whereas intragastric and intraintestinal administrations are invasive and requires intensive surgical training. Also, taking the oneweek recovery period into account, the throughput is lower for intragastric and intraintestinal administrations compared to oral gavage. A significant disadvantage of oral gavage is, however, the very limited correlation to man, whereas a good correlation exists for intragastric administration. This is an important aspect to consider, due to the very limited oral bioavailability of biopharmaceuticals.

\subsection{Blood sampling methods}

When evaluating DDS in animal models, the most common readout is a pharmacological effect or pharmacokinetic profiling, either by quantification of blood glucose after dosing biopharmaceuticals such as insulin and GLP-1 or by compound-specific assays such as enzyme-linked immunosorbent assays (ELISA). Thus, collection of blood samples is essential, and as for all aspects of animal studies, this also involves careful consideration of the advantages and drawbacks of the methods available in order to induce least possible stress to the animals. In Figure 5, the used methods for blood sampling can be observed (compiled from studies reported in Table 1 and 2). 
A

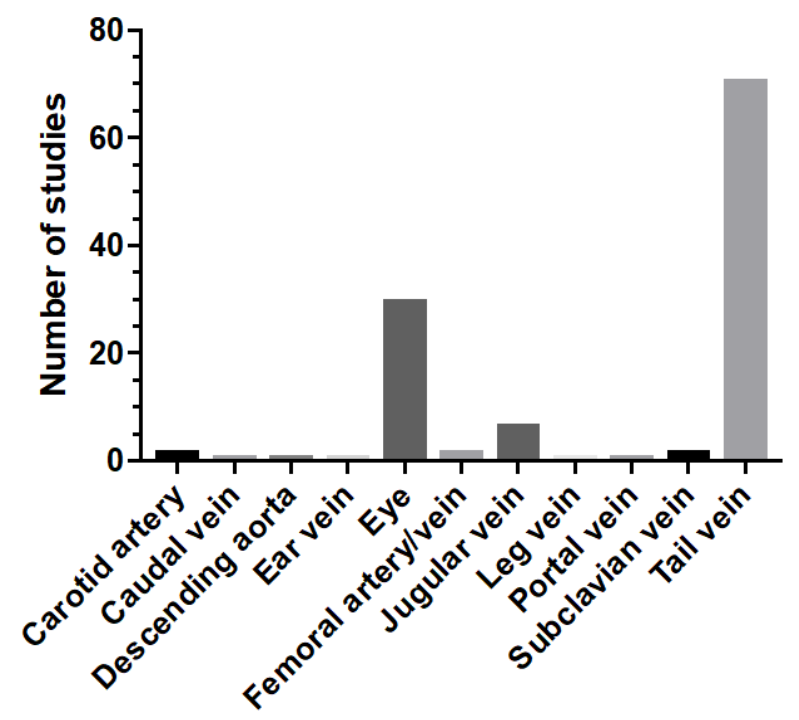

B

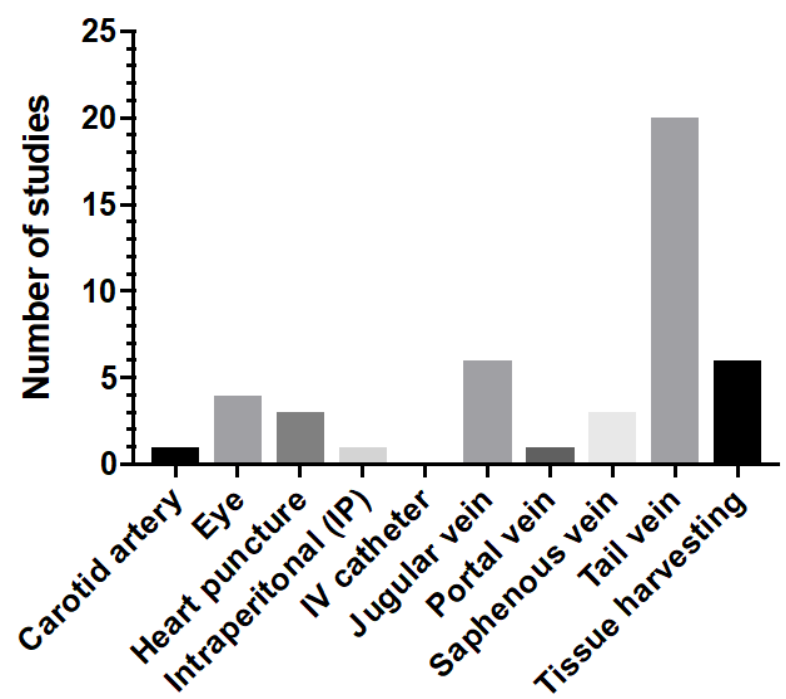

Figure 5: Overview of sampling methods used to evaluate oral bioavailability of insulin (A) and other biopharmaceuticals (B) following in vivo, in situ or ex vivo studies. The graphs are based on the reviewed papers listed in Table 1 and 2.

From Figure 5, it is clear that blood sampling from the tail vein is by far the most commonly used method in mice and rats. However, several methods exist to collect blood from the tail vein $[201,208]$, and it can be performed on the animals either in conscious or anaesthetized state. One approach is to use a restrainer, where the animal enters with their head first and the tail is secured in place by a plug or stopper [207]. For minimizing applying stress to the animals, a red or dark tube is favorable [207], together with frequent washing to avoid cross infection and pheromonal deposition [208]. Once having fixated the rat, the blood can be collected either by vein puncturing using a lancet or needle, or by insertion of a temporary surgical cannula for repeated sample collection. Prior to the sampling, the tail can either be dipped into lukewarm water or placed under a heating lamp to ease access to the tail vein [208], and the blood is typically collected using a capillary tube. An alternative is milking of the tail, where a puncture on the vein is conducted, and the blood is milked out. Here, extreme care must be taken not to rub the tail too intensely, as this may result in leucocytosis and burns. Administration of local analgesic cream prior to sample collection can reduce the stress induced on the animals [208]. Alternative to a restrainer, a towel [207] or even the hands can be used to wrap the animals, keeping the tail free, but whereas the restrainer only requires one person, two persons are needed for these procedures.

Collection of blood from the eye is the second most used blood sampling method for assessment of orally administered biopharmaceuticals (Figure 5). The animals do need to be anaesthetized during blood sampling, and it is not recommended for repeated blood sampling as there is a potential damage of the eye, and in addition also much stress is induced to the animal [208].

For repeated blood sampling, insertion of a cannula should be considered in order to reduce the stress of the animal. According to Figure 5, the jugular vein or alternatively the carotid artery are commonly used in rats, although these methods require intensive surgical training of the research personnel. The surgery is conducted under full anesthesia, and blood samples can be collected in either the anaesthetized or 
conscious state. During surgery, the jugular vein or carotid artery is localized, a small incision is made into the vein or artery and the cannula is carefully inserted and securely fastened. For studies with conscious animals, the cannula is tunneled under the skin to exit in the neck and a harness is employed $[207,208]$. The surgery must be done in a clean environment to avoid infections. The considerations regarding the choice of cannula are as described for intragastric and intraintestinal administrations in section 6.3. When collecting blood, the cannula is flushed with sterile saline added anticoagulant between sample collection, and it is highly important to minimize dilution of the blood by using the lowest possible volume of saline. Heparin and EDTA are the most commonly used anticoagulants, and it is of course important to consider a potential interference of the anticoagulant with the biopharmaceutical in the analytical assay. Blood sampling from the oral cavity or the sublingual tongue vein is also a possibility. This is a fast and easy method, but there is a significant risk of contamination of these samples when the biopharmaceutical is dosed using oral gavage. Moreover, this method can only be conducted in conscious state, and requires restrain of the animals hence, risk of inducing unnecessary stress to the animals.

\subsection{Analytical methods}

An overview of the analytical methods used after drug administration is given in Figure 6 . When evaluating insulin, blood glucose is the most common readout (Figure 6A). Besides, providing information of the pharmacodynamics regarding the effect of the administered biopharmaceutical, it is also a valuable tool to continuously monitor the animal burden while conducting the experiment, and thereby, preventing hypoglycemia in the animals. For testing other biopharmaceuticals than insulin, the preferred analytical method is compound-specific assays such as ELISA and radioimmunoassays providing pharmacokinetic data (Figure 6B), and these methods are often second choice when evaluating insulin-loaded DDS.

Supplementary to the aforementioned methods, microscopic and spectroscopic techniques can be used. Here, information regarding deposition and mechanistic behavior of the DDS can be gained. Those methods are usually conducted after euthanisation, and do therefore only provide information for specific time points. Consequently, if using these methods, more animals are used to assess the in vivo faith of a DDS over time. Alternative methods such as single photon emission computed tomography/computerized tomography (SPECT/CT) can be considered, and here the labeled DDS is administered via the chosen route of administration, and the in vivo faith of the administered sample is followed over time [209]. A significant drawback of this approach is, however, that it requires very expensive equipment and radiolabeling of the test compounds immediately prior to administration. However, the method allows for collection of images of whole animals, the distribution of the label can be quantified, and the method also allows for 3D imaging [209]. Fluorescence detection in animals is also possible, but can be difficult and also demands labeling of the DDS (or biopharmaceutical) with a fluorescence probe [210]. 
A

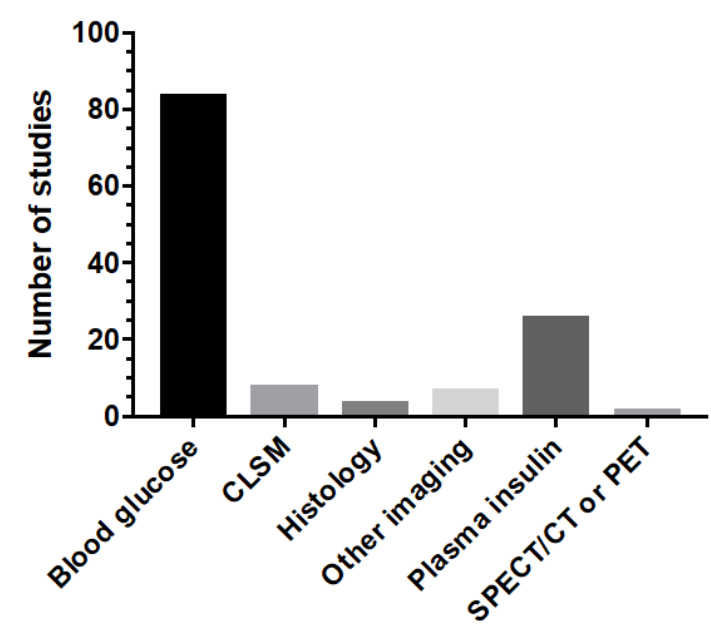

\section{B}

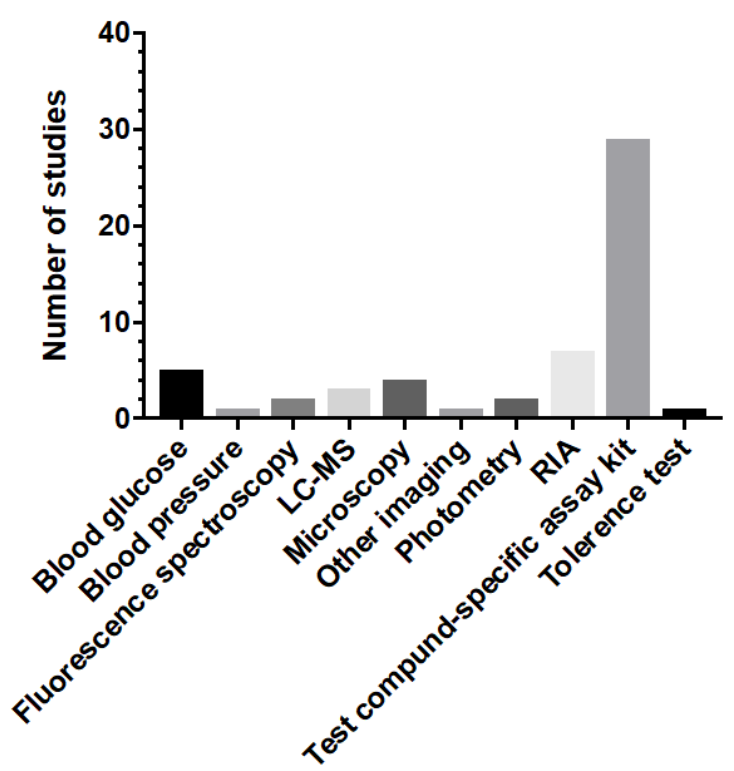

Figure 6: Overview of the analytical methods used to evaluate oral bioavailability of insulin (A) and other biopharmaceuticals (B) in vivo, in situ or ex vivo. This is based on the reviewed papers listed in Table 1 and 2.

\section{Combining and correlating models}

IVIVC (also referred to as in vivo in vitro relationship) is a major area of interest both for academia and industry, and is included in both the European Medicines Agency (EMA) and the Food \& Drug Administration (FDA) guidelines [12]. A recent review by Sjögren et al. [12], thoroughly addresses IVIVC and its applications in relation to characterization of DDS, and it will be presented here in brief. IVIVC is mathematically derived as the predicted correlation between in vitro dissolution and/or cell models and in vivo exposure, yet the term is often used to link in vitro behavior to clinical prediction or results [12]. Knowledge about IVIVC is highly important, as it is used for understanding how, and to which extent, changes in the DDS or manufacturing process influence clinical safety and efficacy. Thus, it is a very important tool from an industrial and regulatory perspective, as it is also used as a quality control parameter after product launch [12].

\section{Conclusions}

Despite the increasing interest in oral delivery of biopharmaceuticals, crucial gaps still exist in relation to knowledge and development of animal models and suitable experimental settings for assessment of biopharmaceuticals dosed by the oral route. As of today, most knowledge of the assessment of oral drugs and the correlation between animal and human studies is based on small molecules. When evaluating orally administered biopharmaceuticals, it is even more crucial to keep in mind that the animal models will merely be models, and as the bioavailability is expected to be very low thorough considerations are essential for all the experimental details, in order to minimize experimental variability and risk of false readouts. This review provides an overview of some of the most important factors influencing the assessment of oral biopharmaceuticals. The review describes the available models and experimental setting used for testing biopharmaceuticals and serves to provide an overview of which animals and methods are 
commonly used when testing oral delivery of biopharmaceuticals. Furthermore, it addresses considerations related to use of anesthesia and the effect this can have on the readout of the studies. Likewise, considerations related to blood sampling procedures and analytical methods are discussed in this review. It is impossible to generalize on which models and methods to utilize in specific studies, but this review presents the advantages and disadvantages of the various methods used so far, hence easing the test designs regarding animal models and methods for the evaluation of biopharmaceuticals to be administered by the oral route.

\section{Conflicts of interest}

None

\section{Acknowledgements}

The authors acknowledge Dr. Tri-Hung Nguyen and Prof. Christopher J. Porter (Monash University, Melbourne, Australia) for valuable scientific discussions and introduction to in vivo studies. Dr. Peter Thygesen (Novo Nordisk, Måløv), Dr. Ulrich Werner, Mario Funke, Dominik Hartmann and Dr. Melissa Besenius (Sanofi, Frankfurt) are also thanked for valuable discussions. Nanna Bild, Technical University of Denmark is acknowledged for the drawing of the schematics. Furthermore, Mechthild Schmitt and Maxim Antopolski (Faculty of Pharmacy, University of Helsinki) are thanked for providing the SPECT-CT images shown in the graphical abstract. Last, Mathilde Caldera (University of Copenhagen) is thanked for always being helpful and providing valuable inputs for setting up in vivo studies.

\section{Funding}

The research leading to these results has received support from the Innovative Medicines Initiative Joint Undertaking under grant agreement no 115363 resources which are composed of financial contribution from the European Union's Seventh Framework Programme (FP7/2007-2013) and EFPIA companies' in kind contribution (SHH). The Danish Research Council for Technology and Production (FTP) (project DFF-400400120B) is acknowledged for financial support (LHN), and in addition, the Danmarks Grundforskningsfonds (project DNRF122) and Villum Fondens Center for Intelligent Drug Delivery and Sensing Using Microcontainers and Nanomechanics (IDUN) is acknowledged.

\section{References}

[1] J.H. Hamman, G.M. Enslin, A.F. Kotzé, Oral delivery of peptide drugs, BioDrugs. 19 (2005) 165-177. doi:10.2165/00063030-200519030-00003.

[2] Global peptide therapeutics pipeline insight 2015, ID 3096565. (2015). http://www.researchandmarkets.com/publication/msloabz/global_peptide_therapeutics_pipeline_i nsighGlobal (accessed November 1, 2016).

[3] B.F. Choonara, Y.E. Choonara, P. Kumar, D. Bijukumar, L.C. du Toit, V. Pillay, A review of advanced oral drug delivery technologies facilitating the protection and absorption of protein and peptide molecules, Biotechnol. Adv. 32 (2014) 1269-82. doi:10.1016/j.biotechadv.2014.07.006.

[4] K. Ganguly, K. Chaturvedi, U.A. More, M.N. Nadagouda, T.M. Aminabhavi, Polysaccharide-based micro/nanohydrogels for delivering macromolecular therapeutics, J. Control. Release. 193 (2014) 162-173. doi:10.1016/j.jconrel.2014.05.014.

[5] A.L. Smart, S. Gaisford, A.W. Basit, Oral peptide and protein delivery: intestinal obstacles and commercial prospects, Expert Opin. Drug Deliv. 11 (2014) 1323-35. doi:10.1517/17425247.2014.917077. 
[6] J. Renukuntla, A.D. Vadlapudi, A. Patel, S.H.S. Boddu, A.K. Mitra, Approaches for enhancing oral bioavailability of peptides and proteins, Int. J. Pharm. 447 (2013) 75-93. doi:10.1016/j.ijpharm.2013.02.030.

[7] P.L. Lam, R. Gambari, Advanced progress of microencapsulation technologies: In vivo and in vitro models for studying oral and transdermal drug deliveries, J. Control. Release. 178 (2014) 25-45. doi:10.1016/j.jconrel.2013.12.028.

[8] S.R. Hwang, Y. Byun, Advances in oral macromolecular drug delivery, Expert Opin. Drug Deliv. 11 (2014) 1-13. doi:10.1517/17425247.2014.945420.

[9] P. Colombo, F. Sonvico, G. Colombo, R. Bettini, Novel platforms for oral drug delivery, Pharm. Res. 26 (2009) 601-611. doi:10.1007/s11095-008-9803-0.

[10] E. Moroz, S. Matoori, J.C. Leroux, Oral delivery of macromolecular drugs: Where we are after almost 100years of attempts, Adv. Drug Deliv. Rev. 101 (2016) 108-121. doi:10.1016/j.addr.2016.01.010.

[11] J. Iqbal, G. Shahnaz, G. Perera, F. Hintzen, F. Sarti, A. Bernkop-Schnürch, Thiolated chitosan: development and in vivo evaluation of an oral delivery system for leuprolide, Eur. J. Pharm. Biopharm. 80 (2012) 95-102. doi:10.1016/j.ejpb.2011.09.010.

[12] E. Sjögren, B. Abrahamsson, P. Augustijns, D. Becker, M.B. Bolger, M. Brewster, J. Brouwers, T. Flanagan, M. Harwood, C. Heinen, R. Holm, H.P. Juretschke, M. Kubbinga, A. Lindahl, V. Lukacova, U. Münster, S. Neuhoff, M.A. Nguyen, A. Van Peer, C. Reppas, A.R. Hodjegan, C. Tannergren, W. Weitschies, C. Wilson, P. Zane, H. Lennernäs, P. Langguth, In vivo methods for drug absorption Comparative physiologies, model selection, correlations with in vitro methods (IVIVC), and applications for formulation/API/excipient characterization including food effects, Eur. J. Pharm. Sci. 57 (2014) 99-151. doi:10.1016/j.ejps.2014.02.010.

[13] J.M. Gamboa, K.W. Leong, In vitro and in vivo models for the study of oral delivery of nanoparticles, Adv. Drug Deliv. Rev. 65 (2013) 800-810. doi:10.1016/j.addr.2013.01.003.

[14] C.A.S. Bergström, W.N. Charman, C.J.H. Porter, Computational prediction of formulation strategies for beyond-rule-of-5 compounds, Adv. Drug Deliv. Rev. 101 (2016) 6-21. doi:10.1016/j.addr.2016.02.005.

[15] G. Traverso, C.M. Schoellhammer, A. Schroeder, R. Maa, G.Y. Lauwers, B.E. Polat, D.G. Anderson, D. Blankschtein, R. Langer, Microneedles for drug delivery via the gastrointestinal tract, J. Pharm. Sci. 104 (2015) 362-367. doi:10.1002/jps.24182.

[16] V.F. Patel, F. Liu, M.B. Brown, Advances in oral transmucosal drug delivery, J. Control. Release. 153 (2011) 106-116. doi:10.1016/j.jconrel.2011.01.027.

[17] M. Morishita, N.A. Peppas, Is the oral route possible for peptide and protein drug delivery?, Drug Discov. Today. 11 (2006) 905-10. doi:10.1016/j.drudis.2006.08.005.

[18] F. Antunes, F. Andrade, D. Ferreira, H.M. Nielsen, B. Sarmento, Models to predict intestinal absorption of therapeutic peptides and proteins, Curr. Drug Metab. 14 (2013) 4-20. doi:10.2174/138920013804545160.

[19] N. Fotaki, Pros and cons of methods used for the prediction of oral drug absorption, Expert Rev. Clin. Pharmacol. 2 (2009) 195-208. doi:10.1586/17512433.2.2.195.

[20] G. Camenisch, J. Alsenz, H. Van De Waterbeemd, G. Folkers, Estimation of permeability by passive diffusion through Caco-2 cell monolayers using the drugs' lipophilicity and molecular weight, Eur. J. Pharm. Sci. 6 (1998) 313-319. doi:10.1016/S0928-0987(97)10019-7.

[21] A. Bayat, F.A. Dorkoosh, A.R. Dehpour, L. Moezi, B. Larijani, H.E. Junginger, M. Rafiee-Tehrani, Nanoparticles of quaternized chitosan derivatives as a carrier for colon delivery of insulin: Ex vivo and in vivo studies, Int. J. Pharm. 356 (2008) 259-266. doi:10.1016/j.ijpharm.2007.12.037.

[22] E. Déat-Lainé, V. Hoffart, G. Garrait, J.F. Jarrige, J.M. Cardot, M. Subirade, E. Beyssac, Efficacy of mucoadhesive hydrogel microparticles of whey protein and alginate for oral insulin delivery, Pharm. Res. 30 (2013) 721-734. doi:10.1007/s11095-012-0913-3.

[23] L. Hovgaard, H. Jacobs, D.E. Wilson, S.W. Kim, Stabilization of insulin by alkylmaltosides. B. Oral absorption in vivo in rats, Int. J. Pharm. 132 (1996) 115-121. doi:10.1016/0378-5173(95)04414-0. 
[24] K. Sonaje, Y.-H. Lin, J.-H. Juang, S.-P. Wey, C.-T. Chen, H.-W. Sung, In vivo evaluation of safety and efficacy of self-assembled nanoparticles for oral insulin delivery, Biomaterials. 30 (2009) 2329-39. doi:10.1016/j.biomaterials.2008.12.066.

[25] M. Trotta, M.E. Carlotti, M. Gallarate, G.P. Zara, E. Muntoni, L. Battaglia, Insulin-loaded SLN prepared with the emulsion dilution technique: In vivo tracking of nanoparticles after oral administration to rats, J. Dispers. Sci. Technol. 32 (2011) 1041-1045. doi:10.1080/01932691.2010.488497.

[26] N. Li, X.-R. Li, Y.-X. Zhou, W.-J. Li, Y. Zhao, S.-J. Ma, J.-W. Li, Y.-J. Gao, Y. Liu, X.-L. Wang, D.-D. Yin, The use of polyion complex micelles to enhance the oral delivery of salmon calcitonin and transport mechanism across the intestinal epithelial barrier, Biomaterials. 33 (2012) 8881-92. doi:10.1016/j.biomaterials.2012.08.047.

[27] M. Niu, Y. Tan, P. Guan, L. Hovgaard, Y. Lu, J. Qi, R. Lian, X. Li, W. Wu, Enhanced oral absorption of insulin-loaded liposomes containing bile salts: A mechanistic study, Int. J. Pharm. 460 (2014) 119130. doi:10.1016/j.ijpharm.2013.11.028.

[28] Y. Zhang, X. Lin, X. Du, S. Geng, H. Li, H. Sun, X. Tang, W. Xiao, pH-sensitive thiolated nanoparticles facilitate the oral delivery of insulin in vitro and in vivo, J. Nanoparticle Res. 17 (2015) 1-11. doi:10.1007/s11051-014-2847-7.

[29] A.M.M. Sadeghi, M.R. Avadi, S. Ejtemaimehr, S. Abashzadeh, A. Partoazar, F. Dorkoosh, M. Faghihi, M. Rafiee-Tehrani, H.E. Junginger, Development of a gas empowered drug delivery system for peptide delivery in the small intestine, J. Control. Release. 134 (2009) 11-17. doi:10.1016/j.jconrel.2008.10.012.

[30] L. Yin, J. Ding, L. Fei, M. He, F. Cui, C. Tang, C. Yin, Beneficial properties for insulin absorption using superporous hydrogel containing interpenetrating polymer network as oral delivery vehicles, Int. J. Pharm. 350 (2008) 220-229. doi:10.1016/j.ijpharm.2007.08.051.

[31] X. Li, S. Guo, C. Zhu, Q. Zhu, Y. Gan, J. Rantanen, U.L. Rahbek, L. Hovgaard, M. Yang, Intestinal mucosa permeability following oral insulin delivery using core shell corona nanolipoparticles, Biomaterials. 34 (2013) 9678-9687. doi:10.1016/j.biomaterials.2013.08.048.

[32] G. Sandri, M.C. Bonferoni, S. Rossi, F. Ferrari, C. Boselli, C. Caramella, Insulin-loaded nanoparticles based on N-trimethyl chitosan: in vitro (Caco-2 model) and ex vivo (excised rat jejunum, duodenum, and ileum) evaluation of penetration enhancement properties, AAPS PharmSciTech. 11 (2010) 36271. doi:10.1208/s12249-010-9390-3.

[33] A. Verma, S. Sharma, P.K. Gupta, A. Singh, B.V. Teja, P. Dwivedi, G.K. Gupta, R. Trivedi, P.R. Mishra, Vitamin B12 functionalized layer by layer calcium phosphate nanoparticles: A mucoadhesive and pH responsive carrier for improved oral delivery of insulin, Acta Biomater. 31 (2016) 288-300. doi:10.1016/j.actbio.2015.12.017.

[34] A. Fasano, S. Uzzau, Modulation of intestinal tight junctions by zonula occludens toxin permits enteral administration of insulin and other macromolecules in an animal model, J. Clin. Invest. 99 (1997) 1158-1164. doi:10.1172/JCI119271.

[35] H. He, J. Sheng, A.E. David, Y.M. Kwon, J. Zhang, Y. Huang, J. Wang, V.C. Yang, The use of low molecular weight protamine chemical chimera to enhance monomeric insulin intestinal absorption, Biomaterials. 34 (2013) 7733-7743. doi:10.1016/j.biomaterials.2013.06.047.

[36] C. Damgé, P. Maincent, N. Ubrich, Oral delivery of insulin associated to polymeric nanoparticles in diabetic rats, J. Control. Release. 117 (2007) 163-170. doi:10.1016/j.jconrel.2006.10.023.

[37] K. Iwanaga, S. Ono, K. Narioka, M. Kakemi, K. Morimoto, S. Yamashita, Y. Namba, O. Naoto, Application of surface-coated liposomes for oral delivery of peptide: Effects of coating the liposome's surface on the GI transit of insulin, J. Pharm. Sci. 88 (1999) 248-252. doi:10.1021/js980235x.

[38] J. Shimoda, H. Onishi, Y. Machida, Bioadhesive characteristics of chitosan microspheres to the mucosa of rat small intestine, Drug Dev. Ind. Pharm. 27 (2001) 567-76. doi:10.1081/DDC100105182. 
[39] A. Tuesca, K. Nakamura, M. Morishita, J. Joseph, N. Peppas, A. Lowman, Complexation hydrogels for oral insulin delivery: Effects of polymer dosing on in vivo efficacy, J. Pharm. Sci. 97 (2008) 26072618. doi:10.1002/jps.21184.

[40] E.-S. Khafagy, R. Iwamae, N. Kamei, M. Takeda-Morishita, Region-dependent role of cell-penetrating peptides in insulin absorption across the rat small intestinal membrane, AAPS J. 17 (2015) 14271437. doi:10.1208/s12248-015-9804-y.

N. Kamei, M. Morishita, Y. Kanayama, K. H Watanabe, K. Takayama, Molecular imaging analysis of intestinal insulin absorption boosted by cellpenetrating peptides by using positron emission tomography, J. Control. Release. 146 (2010) 16-22. doi:10.1016/j.jconrel.2010.05.004.

[42] N. Ahmad, M.C.I. Mohd Amin, I. Ismail, F. Buang, Enhancement of oral insulin bioavailability: in vitro and in vivo assessment of nanoporous stimuli-responsive hydrogel microparticles, Expert Opin. Drug Deliv. 13 (2016) 621-632. doi:10.1517/17425247.2016.1160889.

[43] Y. Jin, Y. Song, X. Zhu, D. Zhou, C. Chen, Z. Zhang, Y. Huang, Goblet cell-targeting nanoparticles for oral insulin delivery and the influence of mucus on insulin transport, Biomaterials. 33 (2012) 15731582. doi:10.1016/j.biomaterials.2011.10.075.

[44] A. Kadir, M.T.M. Mokhtar, T.W. Wong, Nanoparticulate assembly of mannuronic acid- and guluronic acid-rich alginate: Oral insulin carrier and glucose binder, J. Pharm. Sci. 102 (2013) 4353-4363. doi:10.1002/jps.23742.

[45] N. Reix, A. Parat, E. Seyfritz, R. Van Der Werf, V. Epure, N. Ebel, L. Danicher, E. Marchioni, N. Jeandidier, M. Pinget, Y. Frère, S. Sigrist, In vitro uptake evaluation in Caco-2 cells and in vivo results in diabetic rats of insulin-loaded PLGA nanoparticles, Int. J. Pharm. 437 (2012) 213-220. doi:10.1016/j.ijpharm.2012.08.024.

[46] Z.H. Zhang, Y.L. Zhang, J.P. Zhou, H.X. Lv, Solid lipid nanoparticles modified with stearic acidoctaarginine for oral administration of insulin, Int. J. Nanomedicine. 7 (2012) 3333-3339. doi:10.2147/IJN.S31711.

[47] M. Diop, N. Auberval, A. Viciglio, A. Langlois, W. Bietiger, C. Mura, C. Peronet, A. Bekel, D. Julien David, M. Zhao, M. Pinget, N. Jeandidier, C. Vauthier, E. Marchioni, Y. Frere, S. Sigrist, Design, characterisation, and bioefficiency of insulin-chitosan nanoparticles after stabilisation by freezedrying or cross-linking, Int. J. Pharm. 491 (2015) 402-408. doi:10.1016/j.ijpharm.2015.05.065.

[48] F. Cui, F. Qian, Z. Zhao, L. Yin, C. Tang, C. Yin, Preparation, characterization, and oral delivery of insulin loaded carboxylated chitosan grafted poly(methyl methacrylate) nanoparticles, Biomacromolecules. 10 (2009) 1253-1258. doi:10.1021/bm900035u.

[49] V. Gupta, B.H. Hwang, N. Doshi, A. Banerjee, A.C. Anselmo, S. Mitragotri, Delivery of exenatide and insulin using mucoadhesive intestinal devices, Ann. Biomed. Eng. 44 (2016) 1-15. doi:10.1007/s10439-016-1558-x.

[50] F. Cui, F. Qian, Z. Zhao, L. Yin, C. Tang, C. Yin, Preparation, characterization, and oral delivery of insulin loaded carboxylated chitosan grafted poly(methyl methacrylate) nanoparticles, Biomacromolecules. 10 (2009) 1253-1258. doi:10.1021/bm900035u.

[51] S. Sun, N. Liang, Y. Kawashima, D. Xia, F. Cui, Hydrophobic ion pairing of an insulin-sodium deoxycholate complex for oral delivery of insulin, Int. J. Nanomedicine. 6 (2011) 3049-3056. doi:10.2147/IJN.S26450.

[52] B. Sarmento, S. Martins, Oral insulin delivery by means of solid lipid nanoparticles, 2 (2007) 743749. doi:10.1177/193229681300700228.

[53] B. Sarmento, A. Ribeiro, F. Veiga, P. Sampaio, R. Neufeld, D. Ferreira, Alginate/chitosan nanoparticles are effective for oral insulin delivery, Pharm. Res. 24 (2007) 2198-2206. doi:10.1007/s11095-007-9367-4.

[54] B. Sarmento, A. Ribeiro, F. Veiga, D. Ferreira, R. Neufeld, Oral bioavailability of insulin contained in polysaccharide nanoparticles, Biomacromolecules. 8 (2007) 3054-3060. doi:10.1021/bm0703923.

[55] P. Fonte, T. Nogueira, C. Gehm, D. Ferreira, B. Sarmento, Chitosan-coated solid lipid nanoparticles 
enhance the oral absorption of insulin, Drug Deliv. Transl. Res. 1 (2011) 299-308. doi:10.1007/s13346-011-0023-5.

[56] A. Graf, T. Rades, S.M. Hook, Oral insulin delivery using nanoparticles based on microemulsions with different structure-types: Optimisation and in vivo evaluation, Eur. J. Pharm. Sci. 37 (2009) 53-61. doi:10.1016/j.ejps.2008.12.017.

[57] P. Hurkat, A. Jain, A. Jain, S. Shilpi, A. Gulbake, S.K. Jain, Concanavalin A conjugated biodegradable nanoparticles for oral insulin delivery, J. Nanoparticle Res. 14 (2012) 1219. doi:10.1007/s11051-0121219-4.

[58] P. Mukhopadhyay, P.P. Kundu, Chitosan-graft-PAMAM-alginate core-shell nanoparticles: a safe and promising oral insulin carrier in an animal model, RSC Adv. 5 (2015) 93995-94007. doi:10.1039/C5RA17729D.

[59] L. Yin, J. Ding, C. He, L. Cui, C. Tang, C. Yin, Drug permeability and mucoadhesion properties of thiolated trimethyl chitosan nanoparticles in oral insulin delivery, Biomaterials. 30 (2009) 56915700. doi:10.1016/j.biomaterials.2009.06.055.

[60] K. Whitehead, Z. Shen, S. Mitragotri, Oral delivery of macromolecules using intestinal patches: Applications for insulin delivery, J. Control. Release. 98 (2004) 37-45. doi:10.1016/j.jconrel.2004.04.013.

[61] E.J.B. Nielsen, S. Yoshida, N. Kamei, R. Iwamae, E.S. Khafagy, J. Olsen, U.L. Rahbek, B.L. Pedersen, K. Takayama, M. Takeda-Morishita, In vivo proof of concept of oral insulin delivery based on a coadministration strategy with the cell-penetrating peptide penetratin, J. Control. Release. 189 (2014) 19-24. doi:10.1016/j.jconrel.2014.06.022.

[62] C.J. Kirby, Oil-based formulations for oral delivery of therapeutic peptides, J. Liposome Res. 10 (2000) 391-407. doi:10.3109/08982100009031106.

[63] P. Calceti, S. Salmaso, G. Walker, A. Bernkop-Schnürch, Development and in vivo evaluation of an oral insulin-PEG delivery system, Eur. J. Pharm. Sci. 22 (2004) 315-323. doi:10.1016/j.ejps.2004.03.015.

[64] M.K. Marschütz, P. Caliceti, A. Bernkop-Schnürch, Design and in vivo evaluation of an oral delivery system for insulin, Pharm. Res. 17 (2000) 1468-1474. doi:10.1023/A:1007696723125.

[65] M. Werle, B. Loretz, D. Entstrasser, F. Föger, Design and evaluation of a chitosan-aprotinin conjugate for the peroral delivery of therapeutic peptides and proteins susceptible to enzymatic degradation, J. Drug Target. 15 (2007) 327-333. doi:10.1080/10611860701349141.

[66] B. Deutel, M. Greindl, M. Thaurer, A. Bernkop-Schnürch, Novel insulin thiomer nanoparticles: In vivo evaluation of an oral drug delivery system, Biomacromolecules. 9 (2008) 278-285. doi:10.1021/bm700916h.

[67] G. Millotti, F. Laffleur, G. Perera, C. Vigl, K. Pickl, F. Sinner, A. Bernkop-Schnürch, In vivo evaluation of thiolated chitosan tablets for oral insulin delivery, J. Pharm. Sci. 103 (2014) 3165-3170. doi:10.1002/jps.24102.

[68] A.H. Krauland, D. Guggi, A. Bernkop-Schnürch, Oral insulin delivery: The potential of thiolated chitosan-insulin tablets on non-diabetic rats, J. Control. Release. 95 (2004) 547-555. doi:10.1016/j.jconrel.2003.12.017.

[69] V. Grabovac, F. Föger, A. Bernkop-Schnürch, Design and in vivo evaluation of a patch system based on thiolated polymers, Int. J. Pharma. 348 (2008) 169-174. doi:10.1016/j.ijpharm.2007.06.052.

[70] A. Maroni, M. Dorly, D. Curto, S. Salmaso, L. Zema, A. Melocchi, P. Caliceti, A. Gazzaniga, In vitro and in vivo evaluation of an oral multiple-unit formulation for colonic delivery of insulin, Eur. J. Pharm. Biopharm. 108 (2016) 76-82. doi:10.1016/j.ejpb.2016.08.002.

[71] M.A. Momoh, F.C. Kenechukwu, P.O. Nnamani, J.C. Umetiti, Influence of magnesium stearate on the physicochemical and pharmacodynamic characteristics of insulin-loaded Eudragit entrapped mucoadhesive microspheres, Drug Deliv. 7544 (2014) 1-12. doi:10.3109/10717544.2014.898108.

[72] Z.I. Al-Kurdi, B.Z. Chowdhry, S.A. Leharne, N.A. Qinna, M.M.H. Al Omari, A.A. Badwan, Influence of glucosamine on the bioactivity of insulin delivered subcutaneously and in an oral nanodelivery 
[73] F. Yu, Y. Li, C.S. Liu, Q. Chen, G.H. Wang, W. Guo, X.E. Wu, D.H. Li, W.D. Wu, X.D. Chen, Entericcoated capsules filled with mono-disperse micro-particles containing PLGA-lipid-PEG nanoparticles

[74] S. Abbad, Z. Zhang, A.Y. Waddad, W.L.L. Munyendo, H. Lv, J. Zhou, Chitosan-modified cationic amino acid nanoparticles as a novel oral delivery system for insulin, J. Biomed. Nanotechnol. 11 (2015) 486-499. doi:10.1166/jbn.2015.1924.

[75] K.H. Leong, L.Y. Chung, M.I. Noordin, Y. Onuki, M. Morishita, K. Takayama, Lectin-functionalized carboxymethylated kappa-carrageenan microparticles for oral insulin delivery, Carbohydr. Polym. 86 (2011) 555-565. doi:10.1016/j.carbpol.2011.04.070.

[76] L. Zhang, Z. Zhang, N. Li, N. Wang, Y. Wang, S. Tang, L. Xu, Y. Ren, Synthesis and evaluation of a novel $\beta$-cyclodextrin derivative for oral insulin delivery and absorption, Int. J. Biol. Macromol. 61 (2013) 494-500. doi:10.1016/j.ijbiomac.2013.08.034.

[77] Z. Wu, L. Ling, L. Zhou, X. Guo, W. Jiang, Y. Qian, K. Luo, L. Zhang, Novel preparation of PLGA/HP55 nanoparticles for oral insulin delivery, Nanoscale Res. Lett. 7 (2012) 299. doi:10.1186/1556-276X-7299.

[78] B. D'Souza, T. Bhowmik, M.N. Uddin, C. Oettinger, M. D'Souza, Development of b-cyclodextrinbased sustained release microparticles for oral insulin delivery, Drug Dev. Ind. Pharm. Ind Pharm. 9045 (2014) 1-6. doi:10.3109/03639045.2014.947507.

[79] M. Licciardi, G. Pitarresi, G. Cavallaro, G. Giammona, Nanoaggregates based on new polyhydroxyethyl-aspartamide copolymers for oral insulin absorption, Mol. Pharm. 10 (2013) 16441654. doi:10.1021/mp300226d.

[80] L. Yin, J. Ding, J. Zhang, C. He, C. Tang, C. Yin, Polymer integrity related absorption mechanism of superporous hydrogel containing interpenetrating polymer networks for oral delivery of insulin, Biomaterials. 31 (2010) 3347-3356. doi:10.1016/j.biomaterials.2010.01.045.

[81] Y. Zhang, X. Wu, L. Meng, Y. Zhang, R. Ai, N. Qi, H. He, H. Xu, X. Tang, Thiolated Eudragit nanoparticles for oral insulin delivery: Preparation, characterization and in vivo evaluation, Int. J. Pharm. 436 (2012) 341-350. doi:10.1016/j.ijpharm.2012.06.054.

[82] V. Uskokovi, Shape effect in the design of nanowire-coated microparticles as transepithelial drug delivery devices, ACS Nano. 6 (2012) 7832-7841. doi:10.1021/nn3019865.

[83] S. Park, Y. Nho, Y. Lim, H. Kim, Preparation of pH-sensitive poly (vinyl alcohol-g-methacrylic acid) and poly (vinyl alcohol-g-acrylic acid) hydrogels by gamma ray irradiation and their insulin release behavior, J. Appl. Polym. Sci. 91 (2004) 636-643.

[84] Y. Dekel, Y. Glucksam, R. Margalit, Novel fibrillar insulin formulations for oral administration: Formulation and in vivo studies in diabetic mice, J. Control. Release. 143 (2010) 128-135. doi:10.1016/j.jconrel.2009.12.018.

[85] X.Y. Xiong, Q.H. Li, Y.P. Li, L. Guo, Z.L. Li, Y.C. Gong, Pluronic P85/poly(lactic acid) vesicles as novel carrier for oral insulin delivery, Colloids Surfaces B Biointerfaces. 111 (2013) 282-288. doi:10.1016/j.colsurfb.2013.06.019.

[86] P. Mukhopadhyay, K. Sarkar, M. Chakraborty, S. Bhattacharya, R. Mishra, P.P. Kundu, Oral insulin delivery by self-assembled chitosan nanoparticles: In vitro and in vivo studies in diabetic animal model, Mater. Sci. Eng. C. 33 (2013) 376-382. doi:10.1016/j.msec.2012.09.001.

[87] S. Salmaso, S. Bersani, N. Elvassore, A. Bertucco, P. Caliceti, Biopharmaceutical characterisation of insulin and recombinant human growth hormone loaded lipid submicron particles produced by supercritical gas micro-atomisation, Int. J. Pharm. 379 (2009) 51-58. doi:10.1016/j.ijpharm.2009.06.014.

[88] N. Zhang, Q.N. Ping, G.H. Huang, W.F. Xu, Investigation of lectin-modified insulin liposomes as carriers for oral administration, Int. J. Pharm. 294 (2005) 247-259. doi:10.1016/j.ijpharm.2005.01.018.

[89] H. Rachmawati, B.M. Haryadi, K. Anggadiredja, V. Suendo, Intraoral film containing insulin- 
[90] A.K. Agrawal, H. Harde, K. Thanki, S. Jain, Improved stability and antidiabetic potential of insulin

phospholipid microemulsion: Formulation and in vivo hypoglycemic activity study, AAPS PharmSciTech. 16 (2015) 692-703. doi:10.1208/s12249-014-0258-9. containing folic acid functionalized polymer stabilized multilayered liposomes following oral administration, Biomacromolecules. 15 (2014) 350-360. doi:10.1021/bm401580k.

[91] R. Sharma, U. Gupta, N.K. Garg, R.K. Tyagi, N.K. Jain, Surface engineered and ligand anchored nanobioconjugate: An effective therapeutic approach for oral insulin delivery in experimental diabetic rats, Colloids Surfaces B Biointerfaces. 127 (2015) 172-181. doi:10.1016/j.colsurfb.2015.01.035.

[92] K.B. Chalasani, G.J. Russell-Jones, S.K. Yandrapu, P. V. Diwan, S.K. Jain, A novel vitamin B 12-nanosphere conjugate carrier system for peroral delivery of insulin, J. Control. Release. 117 (2007) 421-429. doi:10.1016/j.jconrel.2006.12.003.

[93] F. Cui, K. Shi, L. Zhang, A. Tao, Y. Kawashima, Biodegradable nanoparticles loaded with insulinphospholipid complex for oral delivery: Preparation, in vitro characterization and in vivo evaluation, J. Control. Release. 114 (2006) 242-250. doi:10.1016/j.jconrel.2006.05.013.

[94] Z. Ma, T.M. Lim, L.Y. Lim, Pharmacological activity of peroral chitosan-insulin nanoparticles in diabetic rats, Int. J. Pharm. 293 (2005) 271-280. doi:10.1016/j.ijpharm.2004.12.025.

[95] M.A. Radwan, Enhancement of absorption of insulin-loaded polyisobutylcyanoacrylate nanospheres by sodium cholate after oral and subcutaneous administration in diabetic rats., Drug Dev. Ind. Pharm. 27 (2001) 981-9. doi:10.1081/DDC-100107680.

[96] S. Sajeesh, K. Bouchemal, V. Marsaud, C. Vauthier, C.P. Sharma, Cyclodextrin complexed insulin encapsulated hydrogel microparticles: An oral delivery system for insulin, J. Control. Release. 147 (2010) 377-384. doi:10.1016/j.jconrel.2010.08.007.

[97] W. Wei, G.H. Ma, L.Y. Wang, J. Wu, Z.G. Su, Hollow quaternized chitosan microspheres increase the therapeutic effect of orally administered insulin, Acta Biomater. 6 (2010) 205-209. doi:10.1016/j.actbio.2009.06.005.

[98] K. Kesavan, G. Nath, J.K. Pandit, Preparation and in vitro antibacterial evaluation of gatifloxacin mucoadhesive gellan system., J. Fac. Pharmacy, Tehran Univ. Med. Sci. 18 (2010) 237-46.

[99] Y. Pan, Y. Li, H. Zhao, J. Zhen, H. Xu, G. Wei, J. Hao, F. Cui, Bioadhesive polysaccharide in protein delivery system:chitosan nanoparticles improve the intestinal absorption of insulin in vivo, Int. J. Pharm. 249 (2002) 139-147. doi:10.1016/S0378-5173(02)00486-6.

[100] P.C. Naha, V. Kanchan, P.K. Manna, A.K. Panda, Improved bioavailability of orally delivered insulin using Eudragit-L30D coated PLGA microparticles, J. Microencapsul. 25 (2008) 248-256. doi:10.1080/02652040801903843.

[101] L. Sun, X. Zhang, Z. Wu, C. Zheng, C. Li, Oral glucose- and pH-sensitive nanocarriers for simulating insulin release in vivo, Polym. Chem. 5 (2014) 1999-2009. doi:10.1039/c3py01416a.

[102] S. Sun, N. Liang, H. Piao, H. Yamamoto, Y. Kawashima, F. Cui, Insulin-S.O (sodium oleate) complexloaded PLGA nanoparticles: Formulation, characterization and in vivo evaluation, J. Microencapsul. 27 (2010) 471-478. doi:10.3109/02652040903515490.

[103] R. Yang, R. Gao, F. Li, H. He, X. Tang, The influence of lipid characteristics on the formation, in vitro release, and in vivo absorption of protein-loaded SLN prepared by the double emulsion process, Drug Dev. Ind. Pharm. 37 (2011) 139-48. doi:10.3109/03639045.2010.497151.

[104] L. Zhang, L. Song, C. Zhang, Y. Ren, Improving intestinal insulin absorption efficiency through coadministration of cell-penetrating peptide and hydroxypropyl-ß-cyclodextrin, Carbohydr. Polym. 87 (2012) 1822-1827. doi:10.1016/j.carbpol.2011.10.002.

[105] P. He, Z. Tang, L. Lin, M. Deng, X. Pang, X. Zhuang, X. Chen, Novel biodegradable and pH-sensitive poly(ester amide) microspheres for oral insulin delivery, Macromol. Biosci. 12 (2012) 547-556. doi:10.1002/mabi.201100358.

[106] P. He, H. Liu, Z. Tang, M. Deng, Y. Yang, X. Pang, X. Chen, Poly(ester amide) blend microspheres for oral insulin delivery, Int. J. Pharm. 455 (2013) 259-266. doi:10.1016/j.ijpharm.2013.07.022. 
[107] C.J. Lim, W.C. Shen, Comparison of monomeric and oligomeric transferrin as potential carrier in oral delivery of protein drugs, J. Control. Release. 106 (2005) 273-286. doi:10.1016/j.jconrel.2005.05.001.

[108] Y.H. Lin, F.L. Mi, C.T. Chen, W.C. Chang, S.F. Peng, H.F. Liang, H.W. Sung, Preparation and characterization of nanoparticles shelled with chitosan for oral insulin delivery, Biomacromolecules. 8 (2007) 146-152. doi:10.1021/bm0607776.

[109] M.R. Rekha, C.P. Sharma, Synthesis and evaluation of lauryl succinyl chitosan particles towards oral insulin delivery and absorption, J. Control. Release. 135 (2009) 144-151. doi:10.1016/j.jconrel.2009.01.011.

[110] G. Sharma, K. Wilson, C.F. van der Walle, N. Sattar, J.R. Petrie, M.N. V Ravi Kumar, Microemulsions for oral delivery of insulin: design, development and evaluation in streptozotocin induced diabetic rats, Eur. J. Pharm. Biopharm. 76 (2010) 159-69. doi:10.1016/j.ejpb.2010.07.002.

[111] K. Sonaje, E.Y. Chuang, K.J. Lin, T.C. Yen, F.Y. Su, M.T. Tseng, H.W. Sung, Opening of epithelial tight junctions and enhancement of paracellular permeation by chitosan: Microscopic, ultrastructural, and computed-tomographic observations, Mol. Pharm. 9 (2012) 1271-1279. doi:10.1021/mp200572t.

[112] T. Trenktrog, B.W. Müller, F.M. Specht, J. Seifert, Enteric coated insulin pellets: Development, drug release and in vivo evaluation, Eur. J. Pharm. Sci. 4 (1996) 323-329. doi:10.1016/09280987(95)00162-X.

[113] C.B. Woitiski, R.J. Neufeld, F. Veiga, R.A. Carvalho, I. V. Figueiredo, Pharmacological effect of orally delivered insulin facilitated by multilayered stable nanoparticles, Eur. J. Pharm. Sci. 41 (2010) 556563. doi:10.1016/j.ejps.2010.08.009.

[114] C.Q. Xia, W.C. Shen, Tyrphostin-8 enhances transferrin receptor-mediated transcytosis in Caco-2 cells and increases hypoglycemic effect of orally administered insulin-transferrin conjugate in diabetic rats, Pharm. Res. 18 (2001) 191-195. doi:10.1023/A:1011032502097.

[115] Z. Al-Kurdi, B.Z. Chowdhry, S.A. Leharne, N.A. Qinna, M.M.H. Al-Omari, A.A. Badwan, Influence of glutathione on the bioactivity of subcutaneously or orally administered insulin to rats, Protein Pept. Lett. 22 (2015) 489-496. doi:0929-8665/15.

[116] N.A. Qinna, Q.G. Karwi, N. Al-Jbour, M.A. Al-Remawi, T.M. Alhussainy, K.A. Al-So'ud, M.M.H. Al Omari, A.A. Badwan, Influence of molecular weight and degree of deacetylation of low molecular weight chitosan on the bioactivity of oral insulin preparations, Mar. Drugs. 13 (2015) 1710-1725. doi:10.3390/md13041710.

[117] H. Guo, H. Li, J. Gao, G. Zhao, L. Ling, B. Wang, Q. Gui, Y. Gu, C. Li, Phenylboronic acid-based amphiphilic glycopolymeric nanocarriers for in vivo insulin delivery, Polym. Chem. 7 (2016) 31893199. doi:10.1039/C6PY00131A.

[118] J. Wang, M. Xu, X. Cheng, M. Kong, Y. Liu, C. Feng, X. Chen, Positive/negative surface charge of chitosan based nanogels and its potential influence on oral insulin delivery, Carbohydr. Polym. 136 (2016) 867-874. doi:10.1016/j.carbpol.2015.09.103.

[119] M. Jelvehgari, P.Z. Milani, M.R. Siahi-Shabad, F. Monajjemzadeh, A. Nokhodchi, Z. Azari, H. Valizadeh, In vitro and in vivo evaluation of insulin microspheres containing proteaseinhibitor, Arzneimittelforschung. 61 (2011) 14-22.

[120] R.C. Mundargi, V. Rangaswamy, T.M. Aminabhavi, Poly(N-vinylcaprolactam-co-methacrylic acid) hydrogel microparticles for oral insulin delivery, J. Microencapsul. 28 (2011) 384-394. doi:10.3109/02652048.2011.576782.

[121] E. Lee, J. Lee, S. Jon, A novel approach to oral delivery of insulin by conjugating with low molecular weight chitosan, Bioconjug. Chem. 21 (2010) 1720-1723. doi:10.1021/bc100093v.

[122] B.Y. Kim, J.H. Jeong, K. Park, J.D. Kim, Bioadhesive interaction and hypoglycemic effect of insulinloaded lectin-microparticle conjugates in oral insulin delivery system, J. Control. Release. 102 (2005) 525-538. doi:10.1016/j.jconrel.2004.10.032.

[123] M. Liu, J. Zhang, X. Zhu, W. Shan, L. Li, J. Zhong, Z. Zhang, Y. Huang, Efficient mucus permeation and 
tight junction opening by dissociable "mucus-inert" agent coated trimethyl chitosan nanoparticles for oral insulin delivery, J. Control. Release. 222 (2016) 67-77. doi:10.1016/j.jconrel.2015.12.008.

[124] G. Sharma, C.F. Van Der Walle, M.N. V Ravi Kumar, Antacid co-encapsulated polyester nanoparticles for peroral delivery of insulin: Development, pharmacokinetics, biodistribution and pharmacodynamics, Int. J. Pharm. 440 (2013) 99-110. doi:10.1016/j.ijpharm.2011.12.038.

[125] U. Ubaidulla, Y. Sultana, F.J. Ahmed, R.K. Khar, A.K. Panda, Chitosan phthalate microspheres for oral delivery of insulin: Preparation, characterization, and in vitro evaluation, Drug Deliv. 14 (2007) 1923. doi:10.1080/10717540600559478.

[126] H.J. Cho, J. Oh, M.K. Choo, J.I. Ha, Y. Park, H.J. Maeng, Chondroitin sulfate-capped gold nanoparticles for the oral delivery of insulin, Int. J. Biol. Macromol. 63 (2014) 15-20. doi:10.1016/j.ijbiomac.2013.10.026.

[127] D.R. Bhumkar, H.M. Joshi, M. Sastry, V.B. Pokharkar, Chitosan reduced gold nanoparticles as novel carriers for transmucosal delivery of insulin, Pharm. Res. 24 (2007) 1415-1426. doi:10.1007/s11095007-9257-9.

[128] M. Cui, W. Wu, L. Hovgaard, Y. Lu, D. Chen, J. Qi, Liposomes containing cholesterol analogues of botanical origin as drug delivery systems to enhance the oral absorption of insulin, Int. J. Pharm. 489 (2015) 277-284. doi:10.1016/j.ijpharm.2015.05.006.

[129] D. Sakloetsakun, S. Dünnhaupt, J. Barthelmes, G. Perera, A. Bernkop-Schnürch, Combining two technologies: Multifunctional polymers and self-nanoemulsifying drug delivery system (SNEDDS) for oral insulin administration, Int. J. Biol. Macromol. 61 (2013) 363-372. doi:10.1016/j.ijbiomac.2013.08.002.

[130] A. Viehof, L. Javot, A. Béduneau, Y. Pellequer, A. Lamprecht, Oral insulin delivery in rats by nanoparticles prepared with non-toxic solvents, Int. J. Pharm. 443 (2013) 169-174. doi:10.1016/j.ijpharm.2013.01.017.

[131] T.A. Sonia, M.R. Rekha, C.P. Sharma, Bioadhesive hydrophobic chitosan microparticles for oral delivery of insulin: In vitro characterization and in vivo uptake studies, J. Appl. Polym. Sci. 119 (2011) 2902-2910. doi:10.1002/app.32979.

[132] M. Alibolandi, F. Alabdollah, F. Sadeghi, M. Mohammadi, K. Abnous, M. Ramezani, F. Hadizadeh, Dextran-b-poly(lactide-co-glycolide) polymersome for oral delivery of insulin: In vitro and in vivo evaluation, J. Control. Release. 227 (2016) 58-70. doi:10.1016/j.jconrel.2016.02.031.

[133] N. Zhang, Q. Ping, G. Huang, W. Xu, Y. Cheng, X. Han, Lectin-modified solid lipid nanoparticles as carriers for oral administration of insulin, Int. J. Pharm. 327 (2006) 153-159. doi:10.1016/j.ijpharm.2006.07.026.

[134] E. Ma, H. Ma, Z. Liu, C. Zheng, M. Duan, In vitro and in vivo evaluation of a novel oral insulin formulation, Acta Pharmacol. Sin. 27 (2006) 1382-1388. doi:10.1111/j.1745-7245.2006.00424.x.

[135] L.K. Tomar, C. Tyagi, S.S. Lahiri, H. Singh, Poly(PEGDMA-MAA) copolymeric micro and nanoparticles for oral insulin delivery, Polym. Adv. Technol. 22 (2011) 1760-1767. doi:10.1002/pat.1669.

[136] Z. Li, J. Chen, W. Sun, Y. Xu, Investigation of archaeosomes as carriers for oral delivery of peptides, Biochem. Biophys. Res. Commun. 394 (2010) 412-417. doi:10.1016/j.bbrc.2010.03.041.

[137] H. Sun, D. Liu, Y. Li, X. Tang, Y. Cong, Preparation and in vitro/ in vivo characterization of entericcoated nanoparticles loaded with the antihypertensive peptide VLPVPR, Int. J. Nanomedicine. 9 (2014) 1709-1716. doi:10.2147/IJN.S56092.

[138] S. Dünnhaupt, J. Barthelmes, J. Iqbal, G. Perera, C.C. Thurner, H. Friedl, A. Bernkop-Schnürch, In vivo evaluation of an oral drug delivery system for peptides based on S-protected thiolated chitosan, J. Control. Release. 160 (2012) 477-485. doi:10.1016/j.jconrel.2012.04.020.

[139] H.L. Luessen, B.J. de Leeuw, M.W. Langemeÿer, A.B. de Boer, J.C. Verhoef, H.E. Junginger, Mucoadhesive polymers in peroral peptide drug delivery. VI. Carbomer and chitosan improve the intestinal absorption of the peptide drug buserelin in vivo, Pharm. Res. 13 (1996) 1668-1672. doi:10.1023/A:1016488623022.

[140] M. Wang, Y. Zhang, J. Feng, T. Gu, Q. Dong, X. Yang, Y. Sun, Y. Wu, Y. Chen, W. Kong, Preparation, 
characterization, and in vitro and in vivo investigation of chitosan-coated poly (d, I-lactide-coglycolide) nanoparticles for intestinal delivery of exendin-4, Int. J. Nanomedicine. 8 (2013) 11411154. doi:10.2147/IJN.S41457.

[141] C. Chen, X. Zhu, Y. Dou, J. Xu, J. Zhang, T. Fan, J. Du, K. Liu, Y. Deng, L. Zhao, Y. Huang, Exendin-4 loaded nanoparticles with a lipid shell and aqueous core containing micelles for enhanced intestinal absorption, J. Biomed. Nanotechnol. 11 (2015) 865-876. doi:10.1166/jbn.2015.1971.

[142] Y.S. Youn, S.Y. Chae, S. Lee, M.J. Kwon, H.J. Shin, K.C. Lee, Improved peroral delivery of glucagon-like peptide- 1 by site-specific biotin modification: design, preparation, and biological evaluation, Eur. J. Pharm. Biopharm. 68 (2008) 667-75. doi:10.1016/j.ejpb.2007.07.009.

[143] X. Li, C. Wang, R. Liang, F. Sun, Y. Shi, A. Wang, W. Liu, K. Sun, Y. Li, The glucose-lowering potential of exenatide delivered orally via goblet cell- targeting nanoparticles, Pharm. Res. 32 (2015) 1017-1027. doi:10.1007/s11095-014-1513-1.

[144] S.Y. Chae, C. Jin, H.J. Shin, Y.S. Youn, S. Lee, K.C. Lee, Preparation, characterization, and application of biotinylated and biotin-PEGylated glucagon-like peptide-1 analogues for enhanced oral delivery, Bioconjugate Chem. 19 (2008) 334-341. doi:10.1021/bc700292v.

[145] J.W. Joseph, J. Kalitsky, S. St-Pierre, P.L. Brubaker, Oral delivery of glucagon-like peptide-1 in a modified polymer preparation normalizes basal glycaemia in diabetic $\mathrm{db} / \mathrm{db}$ mice, Diabetologia. 43 (2000) 1319-28. doi:10.1007/s001250051529.

[146] N. Shrestha, F. Araújo, M.-A. Shahbazi, E. Mäkilä, M.J. Gomes, M. Airavaara, E.I. Kauppinen, J. Raula, J. Salonen, J. Hirvonen, B. Sarmento, H.A. Santos, Oral hypoglycaemic effect of GLP-1 and DPP4 inhibitor based nanocomposites in a diabetic animal model, J. Control. Release. 232 (2016) 113-119. doi:10.1016/j.jconrel.2016.04.024.

[147] F. Araújo, N. Shrestha, M.A. Shahbazi, D. Liu, B. Herranz-Blanco, E.M. Mäkilä, J.J. Salonen, J.T. Hirvonen, P.L. Granja, B. Sarmento, H.A. Santos, Microfluidic assembly of a multifunctional tailorable composite system designed for site specific combined oral delivery of peptide drugs, ACS Nano. 9 (2015) 8291-8302. doi:10.1021/acsnano.5b02762.

[148] F.-Y. Su, E.-Y. Chuang, P.-Y. Lin, Y.-C. Chou, C.-T. Chen, F.-L. Mi, S.-P. Wey, T.-C. Yen, K.-J. Lin, H.-W. Sung, Treatment of chemotherapy-induced neutropenia in a rat model by using multiple daily doses of oral administration of G-CSF-containing nanoparticles, Biomaterials. 35 (2014) 3641-9. doi:10.1016/j.biomaterials.2014.01.020.

[149] Z. Khatun, Nurunnabi, K.J. Cho, Y. Byun, Y.H. Bae, Y. Lee, Oral absorption mechanism and antiangiogenesis effect of taurocholic acid-linked heparin-docetaxel conjugates, J. Control. Release. 177 (2014) 64-73. doi:10.1016/j.jconrel.2013.12.034.

[150] Y. Zheng, Y. Qiu, M.F. Lu, D. Hoffman, T.L. Reiland, Permeability and absorption of leuprolide from various intestinal regions in rabbits and rats, Int. J. Pharm. 185 (1999) 83-92. doi:10.1016/S03785173(99)00146-5.

[151] J. Iqbal, C. Vigl, G. Moser, M. Gasteiger, G. Perera, A. Bernkop-Schnürch, Development and in vivo evaluation of a new oral nanoparticulate dosage form for leuprolide based on polyacrylic acid, Drug Deliv. 18 (2011) 432-40. doi:10.3109/10717544.2011.577108.

[152] P. Uhl, F. Helm, G. Hofhaus, S. Brings, C. Kaufman, K. Leotta, S. Urban, U. Haberkorn, W. Mier, G. Fricker, A liposomal formulation for the oral application of the investigational hepatitis $B$ drug Myrcludex B, Eur. J. Pharm. Biopharm. 103 (2016) 159-166. doi:10.1016/j.ejpb.2016.03.031.

[153] S.A. Moreno-Mendieta, D. Guillén, C. Espitia, R. Hernández-Pando, S. Sanchez, R. Rodríguez-Sanoja, A novel antigen-carrier system: the Mycobacterium tuberculosis Acr protein carried by raw starch microparticles, Int. J. Pharm. 474 (2014) 241-8. doi:10.1016/j.ijpharm.2014.07.041.

[154] T.A.S. Aguirre, M. Rosa, I.S. Coulter, D.J. Brayden, In vitro and in vivo preclinical evaluation of a minisphere emulsion-based formulation (SmPill ${ }^{\circledR}$ ) of salmon calcitonin, Eur. J. Pharm. Sci. 79 (2015) 102-111. doi:10.1016/j.ejps.2015.09.001.

[155] P.J. Sinko, Y.H. Lee, V. Makhey, G.D. Leesman, J.P. Sutyak, H. Yu, B. Perry, C.L. Smith, P. Hu, W.E. J, L.M. Falzone, L.T. McWhorter, J.P. Gilligan, W. Stern, Biopharmaceutical approaches for developing 
and assessing oral peptide delivery strategies and systems: in vitro permeability and in vivo oral absorption of salmon calcitonin (sCT), Pharm. Res. 16 (1999) 527-533. doi:10.1023/A:1018819012405.

[156] V. Gupta, B.H. Hwang, N. Doshi, S. Mitragotri, A permeation enhancer for increasing transport of therapeutic macromolecules across the intestine, J. Control. Release. 172 (2013) 541-549. doi:10.1016/j.jconrel.2013.05.002.

[157] V. Gupta, B.H. Hwang, J. Lee, A.C. Anselmo, N. Doshi, S. Mitragotri, Mucoadhesive intestinal devices for oral delivery of salmon calcitonin, J. Control. Release. 172 (2013) 753-762. doi:10.1016/j.jconrel.2013.09.004.

[158] W.-P. Cheng, C. Thompson, S.M. Ryan, T. Aguirre, L. Tetley, D.J. Brayden, In vitro and in vivo characterisation of a novel peptide delivery system: amphiphilic polyelectrolyte-salmon calcitonin nanocomplexes, J. Control. Release. 147 (2010) 289-97. doi:10.1016/j.jconrel.2010.07.128.

[159] M. Cetin, Y.S. Youn, Y. Capan, K.C. Lee, Preparation and characterization of salmon calcitonin-biotin conjugates, AAPS PharmSciTech. 9 (2008) 1191-7. doi:10.1208/s12249-008-9165-2.

[160] D. Guggi, C.E. Kast, A. Bernkop-Schnürch, In vivo evaluation of an oral salmon calcitonin-delivery system based on a thiolated chitosan carrier matrix, Pharm. Res. 20 (2003) 1989-1994. doi:07248741/03/1200-1989/0.

[161] H.E. Lee, M.J. Lee, C.R. Park, A.Y. Kim, K.H. Chun, H.J. Hwang, D.H. Oh, S.O. Jeon, J.S. Kang, T.S. Jung, G.J. Choi, S. Lee, Preparation and characterization of salmon calcitonin-sodium triphosphate ionic complex for oral delivery, J. Control. Release. 143 (2010) 251-257. doi:10.1016/j.jconrel.2009.12.011.

[162] A. Huang, A. Makhlof, Q. Ping, Y. Tozuka, H. Takeuchi, N-trimethyl chitosan-modified liposomes as carriers for oral delivery of salmon calcitonin, Drug Deliv. 18 (2011) 562-569. doi:10.3109/10717544.2011.596585.

[163] A. Makhlof, M. Werle, Y. Tozuka, H. Takeuchi, A mucoadhesive nanoparticulate system for the simultaneous delivery of macromolecules and permeation enhancers to the intestinal mucosa, J. Control. Release. 149 (2011) 81-88. doi:10.1016/j.jconrel.2010.02.001.

[164] A. Makhlof, S. Fujimoto, Y. Tozuka, H. Takeuchi, In vitro and in vivo evaluation of WGA-carbopol modified liposomes as carriers for oral peptide delivery, Eur. J. Pharm. Biopharm. 77 (2011) 216-24. doi:10.1016/j.ejpb.2010.12.008.

[165] M. Cetin, M.S. Aktas, I. Vural, M. Ozturk, Salmon calcitonin-loaded Eudragit ${ }^{\circledR}$ and Eudragit ${ }^{\circledR}$-PLGA nanoparticles: In vitro and in vivo evaluation, J. Microencapsul. 29 (2012) 156-66. doi:10.3109/02652048.2011.635426.

[166] M. Werle, H. Takeuchi, Chitosan-aprotinin coated liposomes for oral peptide delivery: Development, characterisation and in vivo evaluation, Int. J. Pharm. 370 (2009) 26-32. doi:10.1016/j.ijpharm.2008.11.013.

[167] N. Thirawong, J. Thongborisute, H. Takeuchi, P. Sriamornsak, Improved intestinal absorption of calcitonin by mucoadhesive delivery of novel pectin-liposome nanocomplexes, J. Control. Release. 125 (2008) 236-45. doi:10.1016/j.jconrel.2007.10.023.

[168] C. Prego, D. Torres, E. Fernandez-Megia, R. Novoa-Carballal, E. Quiñoá, M.J. Alonso, Chitosan-PEG nanocapsules as new carriers for oral peptide delivery. Effect of chitosan pegylation degree, J. Control. Release. 111 (2006) 299-308. doi:10.1016/j.jconrel.2005.12.015.

[169] M. Garcia-Fuentes, C. Prego, D. Torres, M.J. Alonso, A comparative study of the potential of solid triglyceride nanostructures coated with chitosan or poly(ethylene glycol) as carriers for oral calcitonin delivery, Eur. J. Pharm. Sci. 25 (2005) 133-43. doi:10.1016/j.ejps.2005.02.008.

[170] K. Gradauer, J. Barthelmes, C. Vonach, G. Almer, H. Mangge, B. Teubl, E. Roblegg, S. Dünnhaupt, E. Fröhlich, A. Bernkop-Schnürch, R. Prassl, Liposomes coated with thiolated chitosan enhance oral peptide delivery to rats, J. Control. Release. 172 (2013) 872-878. doi:10.1016/j.jconrel.2013.10.011.

[171] J. Manosroi, W. Lohcharoenkal, F. Götz, R.G. Werner, W. Manosroi, A. Manosroi, Novel application of polioviral capsid: development of a potent and prolonged oral calcitonin using polioviral binding 
ligand and Tat peptide, Drug Dev. Ind. Pharm. 40 (2014) 1092-100. doi:10.3109/03639045.2013.809533.

[172] H.S. Yoo, T. Park, Biodegradable nanoparticles containing protein-fatty acid complexes for oral delivery of salmon calcitonin, J. Pharm. Sci. 93 (2004) 488-495. doi:10.1002/jps.10573.

[173] I. Lozoya-Agullo, M. Zur, O. Wolk, A. Beig, I. González-Álvarez, M. González-Álvarez, M. MerinoSanjuán, M. Bermejo, A. Dahan, In-situ intestinal rat perfusions for human Fabs prediction and BCS permeability class determination: Investigation of the single-pass vs. the Doluisio experimental approaches, Int. J. Pharm. 480 (2015) 1-7. doi:10.1016/j.ijpharm.2015.01.014.

[174] I. Lozoya-Agullo, M. Zur, A. Beig, N. Fine, Y. Cohen, M. González-Álvarez, M. Merino-Sanjuán, I. González-Álvarez, M. Bermejo, A. Dahan, Segmental-dependent permeability throughout the small intestine following oral drug administration: Single-pass vs. Doluisio approach to in-situ rat perfusion, Int. J. Pharm. 515 (2016) 201-208. doi:10.1016/j.ijpharm.2016.09.061.

[175] U. Fagerholm, M. Johansson, H. Lennernäs, Comparison between permeability coefficients in rat and human jejunum, Pharm. Res. 13 (1996) 1336-1342. doi:10.1023/A:1016065715308.

[176] X. Cao, S.T. Gibbs, L. Fang, H.A. Miller, C.P. Landowski, H.C. Shin, H. Lennernas, Y. Zhong, G.L. Amidon, L.X. Yu, D. Sun, Why is it challenging to predict intestinal drug absorption and oral bioavailability in human using rat model, Pharm. Res. 23 (2006) 1675-1686. doi:10.1007/s11095006-9041-2.

[177] M.A. Lopes, B.A. Abrahim, L.M. Cabral, C.R. Rodrigues, R.M.F. Seiça, F.J. de Baptista Veiga, A.J. Ribeiro, Intestinal absorption of insulin nanoparticles: Contribution of M cells, Nanomedicine Nanotechnology, Biol. Med. 10 (2014) 1139-1151. doi:10.1016/j.nano.2014.02.014.

[178] H.J. Van Kruiningen, A.B. West, B.J. Freda, K.A. Holmes, Distribution of Peyer's patches in the distal ileum, Inflamm. Bowel Dis. 8 (2002) 180-185. doi:10.1097/00054725-200205000-00004.

[179] H. Lennernäs, Regional intestinal drug permeation: Biopharmaceutics and drug development, Eur. J. Pharm. Sci. 57 (2014) 333-341. doi:10.1016/j.ejps.2013.08.025.

[180] H. Lennernäs, S. Nylander, A.-L. Ungell, Jejunal permeability: A comparision between Ussing chambers and in humans, Pharm. Res. 14 (1997) 667-671.

[181] P. Zhang, Y. Xu, X. Zhu, Y. Huang, Goblet cell targeting nanoparticle containing drug-loaded micelle cores for oral delivery of insulin, Int. J. Pharm. 496 (2015) 993-1005. doi:10.1016/j.ijpharm.2015.10.078.

[182] W.H. Barr, S. Riegelman, Intestinal drug absorption and metabolism I: Comparison of methods and models to study physiological factors of in vitro and in vivo intestinal absorption, J. Pharm. Sci. 59 (1970) 154-163. doi:10.1002/jps.2600590204.

[183] A. Jain, S.K. Jain, I-Valine appended PLGA nanoparticles for oral insulin delivery, Acta Diabetol. (2015) 663-676. doi:10.1007/s00592-015-0714-3.

[184] H. van de Waterbeemd, E. Gifford, ADMET in silico modelling: towards prediction paradise?, Nat. Rev. Drug Discov. 2 (2003) 192-204. doi:10.1038/nrd1032.

[185] S.H. Welling, L.K.H. Clemmensen, S.T. Buckley, L. Hovgaard, P.B. Brockhoff, H.H.F. Refsgaard, In silico modelling of permeation enhancement potency in Caco-2 monolayers based on molecular descriptors and random forest, Eur. J. Pharm. Biopharm. 94 (2015) 152-159. doi:10.1016/j.ejpb.2015.05.012.

[186] E. Sjögren, H. Thörn, C. Tannergren, In silico modeling of gastrointestinal drug absorption: predictive performance of three physiologically based absorption models, Mol. Pharm. (2016). doi:10.1021/acs.molpharmaceut.5b00861.

[187] W. Jiang, S. Kim, X. Zhang, R.A. Lionberger, B.M. Davit, D.P. Conner, L.X. Yu, The role of predictive biopharmaceutical modeling and simulation in drug development and regulatory evaluation, Int. J. Pharm. 418 (2011) 151-160. doi:10.1016/j.ijpharm.2011.07.024.

[188] A. Dokoumetzidisa, P. Macheras, IVIVC of controlled release formulations: Physiological-dynamical reasons for their failure, J. Control. Release. 129 (2008) 76-78. doi:10.1016/j.jconrel.2008.04.005.

[189] E.L. McConnell, A.W. Basit, S. Murdan, Measurements of rat and mouse gastrointestinal pH, fluid 
and lymphoid tissue, and implications for in-vivo experiments, J. Pharm. Pharmacol. 60 (2008) 6370. doi:10.1211/jpp.60.1.0008.

[190] A.J.F. King, The use of animal models in diabetes research, Br. J. Pharmacol. 166 (2012) 877-894. doi:10.1111/j.1476-5381.2012.01911.x.

[191] S.J. Morgan, C.S. Elangbam, S. Berens, E. Janovitz, A. Vitsky, T. Zabka, L. Conour, Use of animal models of human disease for nonclinical safety assessment of novel pharmaceuticals, Toxicol. Pathol. 0 (2012) 1-11. doi:10.1177/0192623312457273.

[192] B.O. Roep, M. Atkinson, M. von Herrath, Satisfaction (not) guaranteed: re-evaluating the use of animal models of type 1 diabetes, Nat Rev Immunol. 4 (2004) 989-997. 10.1038/nri1502.

[193] T.S. Fröde, Y.S. Medeiros, Animal models to test drugs with potential antidiabetic activity, J. Ethnopharmacol. 115 (2008) 173-183. doi:10.1016/j.jep.2007.10.038.

[194] M. a Valentovic, N. Alejandro, A. Betts Carpenter, P.I. Brown, K. Ramos, Streptozotocin (STZ) diabetes enhances benzo(alpha)pyrene induced renal injury in Sprague Dawley rats, Toxicol. Lett. 164 (2006) 214-20. doi:10.1016/j.toxlet.2005.12.009.

[195] Y.-C. Lei, J.-S. Hwang, C.-C. Chan, C.-T. Lee, T.-J. Cheng, Enhanced oxidative stress and endothelial dysfunction in streptozotocin-diabetic rats exposed to fine particles, Environ. Res. 99 (2005) 335-43. doi:10.1016/j.envres.2005.03.011.

[196] F. Franconi, G. Seghieri, S. Canu, E. Straface, I. Campesi, W. Malorni, Are the available experimental models of type 2 diabetes appropriate for a gender perspective?, Pharmacol. Res. 57 (2008) 6-18. doi:10.1016/j.phrs.2007.11.007.

[197] J.L. Bussiere, P. Martin, M. Horner, J. Couch, M. Flaherty, L. Andrews, J. Beyer, C. Horvath, Alternative strategies for toxicity testing of species-specific biopharmaceuticals, Int. J. Toxicol. 28 (2009) 230-53. doi:10.1177/1091581809337262.

[198] D.K. Badyal, H. Lata, A.P. Dadhich, Animal models of hypertension and effect of drugs, Indian J. Pharmacol. 35 (2003) 349-362. doi:10.1155/2015/528757.

[199] J.A. Auer, A. Goodship, S. Arnoczky, S. Pearce, J. Price, L. Claes, B. von Rechenberg, M. HofmannAmtenbrinck, E. Schneider, R. Müller-Terpitz, F. Thiele, K.-P. Rippe, D.W. Grainger, Refining animal models in fracture research: seeking consensus in optimising both animal welfare and scientific validity for appropriate biomedical use., BMC Musculoskelet. Disord. 8 (2007) 72. doi:10.1186/14712474-8-72.

[200] L. Pénicaud, P. Ferré, J. Kande, A. Leturque, T. Issad, J. Girard, Effect of anesthesia on glucose production and utilization in rats, Am. J. Physiol. - Endocrinol. Metab. 252 (1987) E365-E369. doi:10.1172/JCI111133.

[201] P. V Turner, T. Brabb, C. Pekow, M.A. Vasbinder, Administration of substances to laboratory animals: routes of administration and factors to consider, J. Am. Assoc. Lab. Anim. Sci. 50 (2011) 600-613.

[202] A.F. Hoggatt, J. Hoggatt, M. Honerlaw, L.M. Pelus, A spoonful of sugar helps the medicine go down: a novel technique to improve oral gavage in mice, J. Am. Assoc. Lab. Anim. Sci. 49 (2010) 329-334.

[203] K. Õkva, E. Tamoševičiute, A. Čižiute, P. Pokk, O. Rukšenas, T. Nevalainen, Refinements for intragastric gavage in rats, Scand. J. Lab. Anim. Sci. 33 (2006) 243-252.

[204] M. Bonnichsen, N. Dragsted, A.K. Hansen, The welfare impact of gavaging laboratory rats, Anim. Welf. 14 (2005) 223-227.

[205] S. Saphier, A. Rosner, R. Brandeis, Y. Karton, Gastro intestinal tracking and gastric emptying of solid dosage forms in rats using X-ray imagining, Int. J. Pharm. 388 (2010) 190-195. doi:10.1016/j.ijpharm.2010.01.001.

[206] W.P. Norred, A simple method for intragastric administration of powdered materials to rats, Lab. Anim. Sci. 33 (1983) 585-586.

[207] P. V Turner, C. Pekow, M.A. Vasbinder, T. Brabb, Administration of substances to laboratory animals: equipment considerations, vehicle selection, and solute preparation, J. Am. Assoc. Lab. Anim. Sci. 50 (2011) 614-27.

[208] S. Parasuraman, R. Raveendran, R. Kesavan, Blood sample collection in small laboratory animals, J. 
Pharmacol. Pharmacother. 1 (2010) 87. doi:10.4103/0976-500X.72350.

[209] S. Harloff-Helleberg, L.A.L. Fliervoet, M. Fan $\varnothing$, M. Schmitt, M. Antopolski, A. Urrti, H.M. Nielsen, Biophysical characterization and in vivo evaluation of sucrose ester-based gels as carriers for oral delivery of biopharmaceuticals, Submitted. (2016).

[210] Q. Jin, L. Feng, D.D. Wang, J.J. Wu, J. Hou, Z.R. Dai, S.G. Sun, J.Y. Wang, G.B. Ge, J.N. Cui, L. Yang, A 1071 highly selective near-infrared fluorescent probe for carboxylesterase 2 and its bioimaging applications in living cells and animals, Biosens. Bioelectron. 83 (2016) 193-199. doi:10.1016/j.bios.2016.04.075. 


\section{Captions}

Figure 1: Graphic showing the in vivo barriers in the intestine following oral administration.

Figure 2: Overview of methods used to evaluate oral bioavailability of insulin (A) and other biopharmaceuticals (B) in vivo, ex vivo and in situ based on reviewed papers listed in Table 1 and 2.

Figure 3: Overview of species used to evaluate oral bioavailability of insulin (A) and other biopharmaceuticals (B) in vivo, in situ or ex vivo. The data are based on reviewed papers, listed in Table 1 and 2.

Figure 4: Effect of anesthesia on blood glucose level in healthy rats after subcutaneous (SC) dosing of insulin. The black arrows indicate momentary inhalation of isoflurane. The curves represent the average of three rats \pm SEM, except for the negative control where $n=1$. Blood samples were collected via the sublingual tongue vein.

Figure 5: Overview of sampling methods used to evaluate oral bioavailability of insulin (A) and other biopharmaceuticals (B) following in vivo, in situ or ex vivo studies. The graphs are based on the reviewed papers listed in Table 1 and 2.

Figure 6: Overview of the analytical methods used to evaluate oral bioavailability of insulin (A) and other biopharmaceuticals (B) in vivo, in situ or ex vivo. This is based on the reviewed papers listed in Table 1 and 2. 
